\title{
An Agency Perspective on the Costs and Benefits of Privatization ${ }^{1}$
}

\author{
David Martimort²
}

April 4, 2005

\begin{abstract}
This paper proposes a unified theoretical framework to discuss the costs and benefits of privatization using the recent advances of Incentive Theory. I begin by presenting a simple model in which the State (the principal) delegates a task (e.g., the production of a public good) to the private sector (the agent). I give and discuss conditions for the "Irrelevance Theorem" due to Sappington and Stiglitz (1987) to hold under complete contracting. I then show how various contract incompletenesses can make either public or private ownership optimal. Finally, I provide critical assessments of these results.
\end{abstract}

\footnotetext{
${ }^{1}$ I thank Patrick Rey and Wilfried Zantman for useful comments on an earlier draft. The excellent comments of two referees have also improved substantially the presentation and organization of the paper. I am deeply indebted to Denis Gromb for his extremely detailed comments.

${ }^{2}$ University of Toulouse, (IDEI, GREMAQ) and Institut Universitaire de France.
} 


\section{Introduction}

The past two decades have witnessed a global wave of privatization in many sectors that were traditionally kept under State control and ownership. Network industries such as telecommunications, energy, water and transportation, are the prime examples of sectors that have simultaneously been opened to competition and experienced major changes in their ownership structures. However, this privatization movement has also spread to other sectors, including education, health care, prison management and garbage collection. ${ }^{1}$ The post-war model of State monopolies is no longer fashionable. The dissatisfaction with State monopolies certainly stems from the reported observation that State ownership sometimes fails to provide services efficiently to the public. $^{2}$

Although, practitioners have embraced privatization programs, economic theory does not provide such a clear case in favor of this governance mode. This paper proposes a comprehensive and unified theoretical framework to discuss the costs and benefits of privatization using recent advances of Incentive Theory. ${ }^{3}$

I begin by presenting a simple model in which the State (the principal) delegates a task to the private sector (the agent). This task may be producing a public good or running some facility. This model is useful for delineating the circumstances under which delegation is costless despite informational problems between the State and the contractor. In this framework, I prove Sappington and Stiglitz (1987)'s fundamental "Irrelevance Theorem" stating that privatization may be, under some conditions, an optimal solution to the delegation problem. Privatization replicates then what can be achieved with public production even though this delegation could a priori suffer from some agency costs.

In fact, the assumptions of the Theorem are rather restrictive. In essence, they describe an environment with complete contracting. When all future contingencies can be written ex ante in the contract between the State and the private owners and when the latter are risk-neutral and not financially constrained, privatization achieves the social optimum

\footnotetext{
${ }^{1}$ As reported by Bortolotti and Siniscalco (2003, p. 23) "almost no sector is left out of the privatization process and [..] the greater part of revenue comes from telecommunications, utilities, finance, industrial and agricultural products and energy".

${ }^{2}$ An extreme example is of course given by the failed experiments in some former socialist countries.

${ }^{3}$ Since its goal is mostly methodological, this survey is deliberately restricted and does not cover theoretical contributions which do not belong to that paradigm except incidentally. Other surveys of the literature include Yarrow (1991), Shleifer (1998), Sheshinski and Lopez-Calva (1999), Shirley and Walsh (2000) and Bortolotti and Siniscalco (2003, Chapter 1). Megginson and Netter (2001) and Bortolotti and Siniscalco (2003) review the empirical literature. A word of caution is in order here. The empirical literature has focused on efficiency as the sole criterion for assessing public and private ownership. Megginson and Netter (2001, p.328) claim for instance that "Implicitly, we assume that the goal of the government is to promote efficiency". See also Lopez-de-Silanes, Shleifer and Vishny (1997) and Megginson, Nash and van Randenborgh (1994) for similar arguments. As such the empirical literature does not address issues related to the distribution of information rents and the trade-off between allocative efficiency and rent extraction which is the theme of this survey.
} 
even under various forms of incomplete information.

The "Irrelevance Theorem" provides an important benchmark against which the costs and benefits of State ownership can be assessed. When complete contracts are not feasible, State intervention may be called for. Once State control matters, one must pay attention to the actual behavior of the State and its internal organization matters. Indeed, the State may itself suffer from various incentive problems, be they between citizens and politicians or between politicians and administrative bureaus. The comparison of private and public ownerships hinges then upon the comparison of agency costs in each structure.

The traditional textbook perspective on government intervention is to view the State as a benevolent social welfare maximizer with a long-term horizon, a strong ability to commit and complete information on all policy-relevant parameters. This view reaches its limits when the incentives of the government (or its components) itself have to be taken into account. Thanks to the recent advances in Incentive Theory, ${ }^{4}$ economists are now more comfortable with a more realistic picture of governments, a picture which puts at the forefront the informational problems which may constraint their interventions.

That perspective is important because it implies that efficiency is not be the sole criterion to judge government intervention. The relevant concept is that of interim efficiency. On top of the usual feasibility constraints, this concept also takes into account the informational constraints faced by the government. ${ }^{5}$ In a second-best world of asymmetric information, the key role of the government is then to reach an optimal balance between efficiency and limiting the socially costly information rents that informed players might derive from those policies. This is the basic lesson of the optimal regulation literature which has flourished over the last twenty years or so. ${ }^{6}$

In a regulatory context, the trade-off between allocative efficiency and rent extraction leads to distortions away from the first-best. Departures from the ideal world of complete contracting create various forms of transaction costs which affect those distortions. Public and private ownerships lead both to different transaction costs. If one takes the normative criterion of interim efficiency as a reference, the optimal governance is the one that comes as close as possible to the interim efficiency frontier.

I list below several contractual incompletenesses and show how they affect the tradeoff between efficiency and rent extraction. For each of them, I discuss their consequences for the comparaison between public and private ownership.

- Lack of Commitment: The State may have a limited ability to commit. For instance, regulatory prices caps may be tightened in the future under the pressure of customers,

\footnotetext{
${ }^{4}$ See Laffont and Martimort (2002) for an overview.

${ }^{5}$ See Holmstrom and Myerson (1983).

${ }^{6}$ See Baron (1989), Laffont and Tirole (1993) and Armstrong and Sappington (2003) among others.
} 
privatization programs may be slowed down or stopped. This lack of commitment is first due to the fundamental difficulty faced to describe future contingencies. In this respect, the State is no different from private parties. However, this lack of commitment can also be rooted into the Constitution itself. Democratic governments have indeed a limited tenure and cannot commit their successors to the policies they choose. This constraint implies that contracts between the government and the private sector are incomplete and leave much scope for renegotiation and ex post bargaining. ${ }^{7}$ This commitment failure creates transaction costs which reduce the ex ante benefits of government intervention. We discuss two possible implications of these commitment failures.

* Hold-up: Assume that a contingency which was not contracted upon ex ante between the State and the firm occurs. In that case, the firm's owner enjoys residual rights of control on the productive assets: he can allocate them to the use he judges best. Under public ownership, the State-owner might be unable to commit to reward ex post the firm's manager for nonverifiable investments that the latter may have undertaken to improve productive efficiency. ${ }^{8}$ For instance, public ownership may give to the State access to information which can be used to reduce the firm's subsidies and extract more rent from the firm's management. Because of this hold-up problem, underinvestments and low power incentives are pervasive in public firms. Instead, under privatization, the State remains at arm's length with the management. The management enjoys some information rent which might suffice to boost its incentives to invest.

* Soft Budget Contraint: It is often argued that public firms suffer from a soft budget constraint. ${ }^{9}$ Even though, ex ante, the State would like to commit not to rescue a public firm if it makes losses; ex post, the State cannot refrain from doing so because there are still gains, be they political or economic, ${ }^{10}$ to continue injecting money. ${ }^{11}$ This soft budget constraint has a perverse effect on the management's ex ante incentives to reduce costs. Private firms are on a harder budget constraint because private investors, lacking the State taxing power, face a greater cost of raising funds. This hard budget constraint in turn fosters the ex ante incentives of the manager to reduce costs.

- Limited Control: Another shortcoming of the State may be its inability to exert com-

\footnotetext{
${ }^{7}$ Laffont and Tirole (1993, Chapter 16) endogenize this limited commitment and argue that this can reduce the threat of regulatory capture.

${ }^{8}$ Examples of such hold-up abound in practice. Spiller (1993) reported that the Jamaican government wanted to renegotiate the license contract with Jamaican Telephone Co. in 1962, four years before the license expired. The company stopped immediately all investments.

${ }^{9}$ The World Bank (1993) reported that, by 1992, the credits directed to the military-industrial sector in Russia was about 21\% GDP; according to Segal (1998), an extreme example of the soft budget constraint.

${ }^{10}$ Note that these benefits are political in the case of a non-benevolent government which values office or wants to cajole some constituency whose payoff is congruent with that of the firm. These benefits are instead economic in the case of a benevolent government which maximizes social welfare.

${ }^{11}$ See Kornai (1986), Kornai, Maskin and Roland (2003), Dewatripont and Maskin (1995), Segal (1998) and Maskin (1999).
} 
plete control over all the firm's activities. For instance, the State may lack the expertise or technology to exert the internal control of the firm, i.e., to control inputs and contracts with suppliers, to restrict access to the capital market, or to design the management's incentive schemes. This internal control may be better exerted by the firm's shareholders.

Under limited control, the grand-contracting framework on which the "Irrelevance Theorem" relies no longer holds. The firm's manager has two masters: the State-regulator who keeps external control on regulated prices and outputs, and the shareholders who retain internal control. These two principals do not cooperate in designing the manager's incentives, which introduces also some transaction costs. The absence of a grandcomprehensive contract affects the rent-efficiency trade-off since it introduces contractual externalities between the two principals. There may be too much rent extraction under private ownership. Of course, that cost of privatization should be balanced with the benefits it might yield in safeguarding the manager's investments.

- Non-Benevolent Governments: A third shortcoming of State control may stem from politicians not being benevolent social welfare maximizers. Instead, they may be biased to favor their constituencies. This imperfect political delegation creates an agency problem between politicians and voters. This agency problem could be solved through the threat of not reelecting incumbent politicians if voters believe that they run public firms in an undesirable way. Alternatively, relinquishing control rights to the private sector puts a constraint on the opportunistic behavior of biased political principals. Privatization may thus replace a missing incentive scheme for politicians.

- Fragmented Governments: Bureaucrats managing public firm are subjected to various and somewhat conflicting incentives. Indeed, the control of public firms is often shared among various government bodies or regulatory agencies having different objectives. Instead, profit maximization provides a clearer objective to the managers of private firms, which might translate into better incentives.

Section 2 describes the basic unifying framework used throughout the paper. The framework is then developed under the various assumptions of contract incompleteness discussed above. This helps to illustrate the consequences of these contractual incompletenesses on the optimal governance mode. I prove the "Irrelevance Theorem" and discuss its scope and limits. Section 3 deals with the commitment problem, with simple models of the hold-up and the soft budget constraint. Section 4 shows the costs and benefits of a limited control by the State. I also show how limited control may be justified from a theoretical viewpoint. Section 5 takes a political economy perspective and highlights the role of privatization as a constraint on politicians. Section 6 briefly discusses incentives in private and public bureaucracies and their impact on the privatization debate. Section 7 concludes. 


\section{A Benchmark: The "Irrelevance Theorem"}

Sappington and Stiglitz (1987)'s seminal paper establishes an important "Irrelevance Theorem". This result shows conditions under public and private ownership are equivalent, i.e., under which the State is indifferent between delegating a productive task to the private sector of keeping production public.

Setting the problem in terms of delegation suggests that the Principal-Agent theory is a relevant paradigm to understand the limits of government and the scope of the public sector. This theory characterizes the agency costs incurred by a principal from delegating a task to an agent. Delegation generally implies that the agent has access to private information that is relevant to the task. In the adverse selection case, information is exogenous and stems from the agent's knowledge of various technological parameters. In the moral hazard case, information is endogenous and stems from the agent's nonobservable choices (e.g. efforts, investments, or technologies). The main lesson of the theory of incentives is that these informational problems generally make delegation costly. To the technological cost of production, one must now add the agency cost of delegation to assess the optimal allocation of resources.

There exists however a small set of assumptions under which delegation is costless. In the context of privatization, that result states that the State is equally well-off performing a task and contracting it out to the private sector. Given the importance of these assumptions, it is useful to state and discuss each of them in turn.

- A1 The agent is risk-neutral.

- A2 The agent is not financially constrained.

- A3 The principal and the agent can enter into a fully binding and complete contract stipulating payments and levels of service ${ }^{12}$ in each possible contingency.

Assumption A1 implies that the firm's owners must be sufficiently diversified or have access to enough financial instruments to hedge their income. Such owners can thus bear the full operational and financial risks that they will face.

Assumption A2 means that investors must have enough funds or collateral to secure a frictionless access to capital markets. Free access to the capital market enables them to purchase the productive assets through the privatization process. Clearly, both A1 and A2 make a case for selling assets to large investors who are both well diversified and collateralized. It also suggests that financial markets should be sufficiently developed.

\footnotetext{
${ }^{12}$ For instance, this may be the quality or the quantity of the good produced.
} 
Finally, Assumption A3 requires that all future contingencies can be perfectly anticipated and written into a contract. Contracts have to be complete. This assumption implicitly requires that contracting take place ex ante, i.e., before any of the contracting partners learns private information.

I can now state the following major result:

"The Irrelevance Theorem": Assume that the State and the private sector have the same production technology. Under assumptions A1, A2 and A3, privatization is a possible solution to the delegation problem. When at least one of these assumptions fails to hold, privatization involves an agency cost and State ownership might be preferable.

Of course, if the private sector has a better technology, privatization could be preferred. Making such an assumption on technologies is however a rather ad hoc approach.

\subsection{A Basic Model}

To prove this theorem, I propose a simple model that will be used throughout the paper. In this model, the firm maximizes its profits defined as:

$$
U=t-\theta q
$$

where $t$ is the monetary transfer received from the State, $q$ is the quantity of good produced, and $\theta$ is a measure of cost efficiency. ${ }^{13}$

This parameter is a binary random variable taking values in $\Theta=\{\underline{\theta}, \bar{\theta}\}$ (with $\Delta \theta=$ $\bar{\theta}-\underline{\theta}>0)$ with respective probabilities $\nu$ and $1-\nu$ which are common knowledge. ${ }^{14}$ Only the firm knows the value of $\theta$. This captures the possible asymmetry of information between the State and the private sector arising under delegation.

Following Laffont and Tirole (1993), I assume that the State maximizes the following objective function:

$$
V=S(q)-(1+\lambda) t+U
$$

where $S(q)$ is the surplus associated with the production of $q$ units of the good. For technical reasons, I assume that $S(0)=0, S^{\prime}>0, S^{\prime \prime}<0$ with the Inada condition $S^{\prime}(0)=+\infty .^{15}$ Note that $S(\cdot)$ may account for externalities and other non-economic

\footnotetext{
${ }^{13}$ Two remarks are in order. First, the variable $q$ could also represents the quality of a good (when verifiable and contractible). For simplicity, I stick to the quantity interpretation in what follows. Second, I have assumed no fixed-cost of production. Fixed-costs could easily be introduced. They would play little role, however, as long as they were observable and verifiable. For most of the paper, except Section 3.5, I will omit them.

${ }^{14}$ For now, I assume that this distribution is exogenous and thus not affected by any choice made by the firm. This is thus a pure adverse selection framework.

${ }^{15}$ These assumptions ensure that the production is positive under all circumstances.
} 
consequences of the firm's activities. Finally, $\lambda$ represents a strictly positive cost of public funds. This assumption captures the idea that regulatory budgets are raised through distortionary taxation in other sectors of the economy.

Using the expression of the firm's profit, the State's objective can be rewritten as

$$
V=S(q)-(1+\lambda) \theta q-\lambda U
$$

The timing of the contracting game between the State and the firm is as follows:

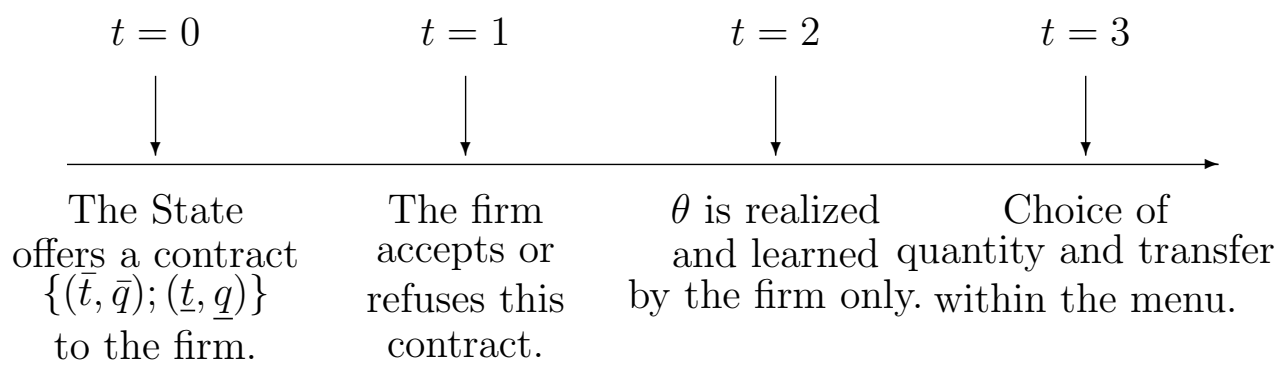

Figure 1: Timing of the delegation game.

The Revelation Principle ${ }^{16}$ allows us to restrict the analysis to contracts, or direct revelation mechanisms which are truthful, i.e., which induce the firm to report the truth on its technological parameter. Those contracts take thus the form $\{(\underline{t}, \underline{q}) ;(\bar{t}, \bar{q})\}$ where $(\underline{t}, q)$ (resp. $(\bar{t}, \bar{q}))$ are the payment and output when the firm is efficient, i.e., when $\theta=\underline{\theta}$ (resp. inefficient, i.e., when $\theta=\bar{\theta}$ ).

Define the information rents of the firm as $\underline{U}=\underline{t}-\underline{\theta} \underline{q}$ and $\bar{U}=\bar{t}-\bar{\theta} \bar{q}$. The incentive constraints imposed by the Revelation Principle can be written as: ${ }^{17}$

$$
\begin{aligned}
& \underline{U} \geq \bar{U}+\Delta \theta \bar{q}, \\
& \bar{U} \geq \underline{U}-\Delta \theta \underline{q} .
\end{aligned}
$$

Constraint (1) ensures that the firm selects $(\underline{t}, q)$ rather than $(\bar{t}, \bar{q})$ when $\theta=\underline{\theta}$. Constraint (2) ensures that the firm selects $(\bar{t}, \bar{q})$ rather than $(\underline{t}, \underline{q})$ when $\theta=\bar{\theta}$.

Under Assumption A3, the State and the firm can sign and remain fully committed to an incentive contract before $\theta$ is realized. Since the firm accepts the contract before learning its type $\theta$, its ex ante participation constraint must be satisfied:

$$
\nu \underline{U}+(1-\nu) \bar{U} \geq 0 .
$$

\footnotetext{
${ }^{16}$ See for instance Laffont and Martimort (2002, Chapter 2).

${ }^{17}$ Note that (1) and (2) imply the monotonicity condition $\underline{q} \geq \bar{q}$.
} 
Constraints (1), (2) and (3) define the set of incentive-feasible contracts. Within the set of interim efficient outcomes, I shall be interested by that giving all bargaining power to the princpal. The principal's problem can then be written as:

$$
\max _{\{(\underline{q}, \underline{U}) ;(\bar{q}, \bar{U})\}} \nu \underbrace{\nu\left(\frac{1}{1+\lambda} S(\underline{q})-\underline{\theta} \underline{q}\right)+(1-\nu)\left(\frac{1}{1+\lambda} S(\bar{q})-\bar{\theta} \bar{q}\right)}_{\text {expected net surplus }}-\frac{\lambda}{1+\lambda} \underbrace{(\nu \underline{U}+(1-\nu) \bar{U})}_{\text {information rent }}
$$

$$
\text { subject to (1), (2) and (3). }
$$

Expression (4) shows that the principal has two objectives. On the one hand, he seeks to maximize the net surplus of production. On the other hand, because $\lambda>0$, he seeks to minimize the firm's rent. These two objectives will be antagonistic and the optimal contract strikes a balance between them.

The solution to this optimization problem is straightforward.

- The principal sets the agent's rent to its minimum, i.e., zero (the firm's participation constraint (3) is binding). Therefore, there are no agency costs.

- The optimal quantities are set to their first-best level ${ }^{18}$

$$
\frac{1}{1+\lambda} S^{\prime}\left(q^{*}(\theta)\right)=\theta
$$

- The firm's rent in the two states of nature can be distributed in many ways. Formally, any pair $(\underline{U}, \bar{U})$ satisfying $\underline{U} \in\left[(1-\nu) \Delta \theta q^{*}(\bar{\theta}),(1-\nu) \Delta \theta q^{*}(\underline{\theta})\right]$ and $\bar{U}=-\frac{\nu}{1-\nu} \underline{U}$ is a solution. Note that, for all these solutions, the inefficient firm runs a loss since $\bar{U} \leq-\nu \Delta \theta q^{*}(\bar{\theta})<0$.

One implementation of the optimum is of particular importance: the "sell-out" contract corresponding to $t(q)=\frac{1}{1+\lambda} S(q)-T$. $T$ is an up-front payment paid by the firm to have the right to produce the service and $\frac{1}{1+\lambda} S(q)$ is the social value of the consumer's surplus (taking into account the discount due to the social cost of public funds). This contract amounts to the State selling the productive assets to private owners for a fixed price $T$ and then paying the firm the full social benefit $\frac{1}{1+\lambda} S(q)$ of production (accounting of course for the cost of public funds).

$T$ is set to extract all ex ante benefit of the firm. It is thus the expected first-best social surplus from running the firm,

$$
T=\underset{\theta}{E}\left(\frac{1}{1+\lambda} S\left(q^{*}(\theta)\right)-\theta q^{*}(\theta)\right)
$$

\footnotetext{
${ }^{18}$ Given the positive cost of public funds, our full information benchmark is not marginal cost pricing but Ramsey pricing.
} 
where $\underset{\theta}{E}(\cdot)$ is the expectation operator with respect to $\theta .{ }^{19}$

Remark 1: Instead of delegating production to the private sector, the State could instead keep production public. The implicit assumption behind the Equivalence Theorem is that, under public ownership, the State produces itself at the same cost than the private sector and thus achieves the same expected welfare. An alternative assumption might be that, the State, as a principal, still delegates production to a public agent (say a bureaucrat) and, by doing so, let this bureaucrat get access to private information. By reinterpretating the delegation model, the corresponding agency costs are still zero. Ownership does not matter under ex ante contracting.

Remark 2: The Theorem does not distinguish between the case where the State only privatizes the service but keeps ownership of the productive assets and the case where the State privatizes both assets and service. Depending on the context, I will use both interpretations in the discussions below.

Remark 3: The private firm to whom the task is delegated is modelled as an individual. There is no separation between ownership and control.

\subsection{Extensions}

- Non-verifiable benefits of ownership: The "sell-out" contract works well because the social value of production $\frac{1}{1+\lambda} S(q)$ can be described ex ante in a contract. In an incomplete contracting environment, these benefits may be hard to specify in advance. The only feasible contracts consist then in allocating ownership of the productive asset between the principal and the agent; a "dummy" contract. If ownership of an asset gives to the owners the rights to the returns associated with that asset (a standard assumption made in the incomplete contracts literature $\left.{ }^{20}\right)$, owners enjoy a benefit $S_{0}(q)$ from running the firm. When there is no externality, $S_{0}(\cdot)$ and $\frac{1}{1+\lambda} S(\cdot)$ are equal and the simple allocation of ownership performs perfectly well. The incompleteness of contract does not limit the contracting ability of the partners. But in the presence of externalities, the private returns from the asset differ from its social value. Private ownership needs to be supplemented by some form of regulation. ${ }^{21,22}$

- Observable but non-verifiable cost parameter: So far, I have assumed that $\theta$ is

\footnotetext{
${ }^{19}$ This solution is similar to that proposed by Loeb and Magat (1979). It can easily be extended to the case of several competing firms bidding for the right of being a franchisee.

${ }^{20}$ See Homlstrom and Milgrom (1991) among others.

${ }^{21}$ Of course, regulatory contracts may suffer from the same incompleteness and be of limited help.

${ }^{22}$ Note also that a simple allocation of ownership still performs well even though the benefit $\frac{1}{1+\lambda} S(\cdot)$ depends on $\theta$ and cannot be specified in a contract (because of the non-verifiability of $\theta$ ) if externalities are absent. This dependence of the social surplus on $\theta$ can arise when, for instance, the quality of the good depends on the technology used by the agent.
} 
not observed by the principal. Suppose instead that it can be observed but not verified, i.e., it cannot be specified in a contract enforced by a Court of Law (another standard assumption in the incomplete contract literature). Then, while the principal and the agent cannot write contingent contracts, they can still write the same incentive contracts as if $\theta$ were non-observable. The simple "sell-out" contract stressed above still implements the first-best in those environments. ${ }^{23}$

- Moral hazard: Suppose that, after having accepted the contract, the agent exerts a non-verifiable effort $e$ affecting the probability $\nu(e)$ that $\theta=\underline{\theta}$. One can think of this effort variable as a lumpy investment in infrastructure, in maintaining existing assets or even in building the management's human capital.

To fix ideas, suppose that this effort can only take two values $e \in\{0,1\}$, with cost $\psi$ for a positive effort and $\nu(1)>\nu(0)$ (with $\Delta \nu=\nu(1)-\nu(0)>0$ ). Let us also assume that performing the high level of effort is efficient, i.e., the following condition holds:

$$
\Delta \nu\left\{\frac{1}{1+\lambda} S\left(q^{*}(\underline{\theta})\right)-\underline{\theta} q^{*}(\underline{\theta})-\left(\frac{1}{1+\lambda} S\left(q^{*}(\bar{\theta})\right)-\bar{\theta} q^{*}(\bar{\theta})\right)\right\} \geq \psi .
$$

This condition simply states that, by exerting the positive effort, the increase in expected welfare corresponding to an increase in the probability of having a low cost covers the cost of incurring this positive effort.

It is straightforward to check that the "sell-out" contract still implements the first-best since it allows to align the firm's objective with that of the State.

The price $T$ paid by the agent to acquire the firm must simply reimburse the agent for the extra cost of effort:

$$
T=\underset{\theta}{E}\left(\frac{1}{1+\lambda} S\left(q^{*}(\theta)\right)-\theta q^{*}(\theta)\right)-\psi,
$$

where the expectation over $\theta$ is taken with the probabilities $\{\nu(1), 1-\nu(1)\}$.

- Principal's risk-aversion: With the sell-out contract the State receives a fixed payoff $T$ irrespective of the state of nature. This insurance may be particularly interesting for small local governments for which the project represents a significant share of the budget. For insurance reasons, such governments may decide to privatize crucial infrastructures and services, such as garbage collection, water systems, transportation, etc...

- Non-benevolent principal: The principal needs not be a benevolent social-welfare maximizer for the "Irrelevance Theorem" to hold. The principal's objective function plays no role. The principal's objective may be biased towards consumers, leading him to favor for low prices. Alternatively, the principal may be biased towards the industry to extract campaign contributions.

\footnotetext{
${ }^{23}$ See Laffont and Martimort (2002, Chapter 6).
} 
- Investment by the principal: The technology may be affected by a non-verifiable but observable investment, performed by the State before contracting with the firm. For instance, the State may own an infrastructure and delegates its management to the private sector as under various franchising systems or public/private partnerships observed in practice. In that case, the State's desire to sell the right of providing services at a higher price $T$ might give it the right incentives to invest. ${ }^{24}$

\subsection{Limits of the "Irrelevance Theorem"}

The "Irrelevance Theorem" has its own limits. Those limits stress the very stringent conditions under which that theorem applies. They also delineate environments where state ownership could a priori (if it was immune to any agency cost or at least suffering from a lower one) strictly dominate private ownership. However, when State ownership appears to dominate, one has also to consider in more details the internal structure of the government and its own incentive problems. This may identify additional costs which affect the nature of the trade-off between public and private ownership.

- Risk-averse firm: Assume that the firm is risk-averse. ${ }^{25}$ The optimal contract must strike a balance between the firm's demand for insurance, which suggests making the firm's ex post rent independent of the state of nature (formally $\underline{U}=\bar{U}$ ), and the need to satisfy the firm's incentive constraint (1). At the optimum, this constraint is binding and a downward distortion in $q(\bar{\theta})$ is needed to reduce the risk borne by the firm. The "sell-out" contract is no longer optimal and the State must retain some equity in the project.

- Financial constraint: The "sell-out" contract relies on the firm's ability to pay upfront the fee $T$. This may not be possible if the firm has little cash available or limited collateral.

Denoting by $\ell$ the value of the firm's other assets, this liability constraint can be written as

$$
\bar{U} \geq-\ell
$$

This constraint is binding when $\ell \leq \nu \Delta \theta q^{*}(\bar{\theta})$. In that case, the financially constrained firm cannot afford the loss in state $\bar{\theta}$ that is needed to satisfy the efficient firm's incentive constraint. Hence, the optimal output has to be distorted away from the first-best. The "sell-out" contract is no longer optimal. Selling the firm at its fair value is not possible under limited liability. ${ }^{26}$

\footnotetext{
${ }^{24}$ See Demski and Sappington (1991) for details on the timing of such a game although their paper is not cast in a regulatory framework.

${ }^{25}$ Asymmetric information vis-à-vis the capital market may justify that risk-averse entrepreneurs have to keep some risk for signaling reasons as in Leland and Pyle (1977) and thus cannot be fully ensured.

${ }^{26}$ See Sappington (1983) for a principal-agent model under adverse selection and limited liability.
} 
- Imperfect commitment: Suppose the State cannot commit itself to a reward structure at the ex ante stage, but only ex post, once the firm knows its cost parameter $\theta$. The firm can then opt out of the contract in any state of nature if it does make a positive profit. The ex ante participation constraint (3) is thus replaced with the following two ex post participation constraints

$$
\begin{aligned}
& \underline{U} \geq 0 \\
& \bar{U} \geq 0 .
\end{aligned}
$$

The ex post constraints are, of course, harder to satisfy than the ex ante constraint (3).

Given the importance of this second-best environment for what follows, let us analyze the State's problem in some details:

$$
\max _{\{(\underline{q}, \underline{U}) ;(\bar{q}, \bar{U})\}} \nu(S(\underline{q})-(1+\lambda) \underline{\theta} \underline{q})+(1-\nu)(S(\bar{q})-(1+\lambda) \bar{\theta} \bar{q})-\lambda(\nu \underline{U}+(1-\nu) \bar{U})
$$

$$
\text { subject to (1), (2), (7) and (8). }
$$

The solution to this two-type adverse selection problem is standard. ${ }^{27}$

- Only the efficient firm's information rent is positive: $\underline{U}^{S B}=\Delta \theta \bar{q}^{S B}$, and $\bar{U}^{S B}=0$. The overall agency cost is therefore positive and equal to $\lambda \nu \Delta \theta \bar{q}^{S B}$.

- The efficient firm's output remains unchanged and is still at its first-best level, $q^{S B}(\underline{\theta})=q^{*}(\underline{\theta})$. However, the inefficient firm's output $q^{S B}(\bar{\theta})$ is distorted below the firstbest to reduce the agency cost:

$$
\frac{1}{1+\lambda} S^{\prime}\left(q^{S B}(\bar{\theta})\right)=\bar{\theta}+\frac{\lambda}{1+\lambda} \frac{\nu}{1-\nu} \Delta \theta
$$

- No commitment: Let us suppose that no contract can ever be written; an extreme form of imperfect commitment. For instance, this may be due to the government's term being finite. Alternatively, this may also stem from output being hard to describe in advance, making it impossible to write any contracts based on output before the cost parameter $\theta$ realizes. To model such an incomplete contracting environment, assume that $\theta$ is non-verifiable but observable ex post by both the State and the firm. After $\theta$ is realized, the State and the firm will bargain over the transfer $t$ and the quantity $q$. Assume also that the agent must make an ex ante investment to improve technology. This effort can thus be only rewarded if the firm receives a sufficiently large part of the ex post social surplus. Otherwise, the hold-up problem ${ }^{28}$ arises and anticipating this outcome, the firm underinvests.

\footnotetext{
${ }^{27}$ See Laffont and Martimort (2002, Chapter 2) and Armstrong and Sappington (2003).

${ }^{28}$ See Williamson (1985) and Section 3.1 below.
} 


\subsection{Practical Relevance of the "Irrelevance Theorem"}

The "Irrelevance Theorem" is unlikely to hold in practice. Private investors always face some sort of financial constraints. To illustrate, consider the privatization process in developing countries. Because local financial markets are underdeveloped, frictions (e.g., informational asymmetries) lead to incomplete diversification and strong financial constraints for local investors. This puts those investors at a disadvantage compared with international investors who have already acquired enough reputational capital to get an easy access to financial markets with less frictions. This argument may help to explain the prevalence of foreign investment in those developing countries and the difficulties found to privatize.

Full commitment (Assumption A3) is also unlikely to hold in practice. Indeed, it requires that the State and the firm have the same information at the time of contracting. Private firms acquiring State assets tend to be preexisting businesses with experience in similar operations likely to give them private information. Conversely, the State or local governments privatizing infrastructures are likely to have acquired private information while managing these assets.

The main value of the "Irrelevance Theorem" is to help organize one's thoughts on the privatization issue. It serves as a benchmark very much in the spirit of the Coase or the Miller-Modigliani Theorems.

\section{Limits to Commitment}

By focusing on full commitment, I have by large ignored one of the most important aspects of ownership: the owner of an asset holds residual rights of control on its use under contingencies that are not specified in a contract ex ante. When commitment is limited, control rights are particularly important because they imply that the asset's owner cannot commit to use this asset ex post (under contingencies not specified in the contract) in a way that does not maximize his payoff. This is a major point of the incomplete contracts literature. ${ }^{29}$ In the context of the privatization debate, it means that the government cannot commit not to intervene ex post in the management of public firms. This creates two sorts of problems: hold-up and soft-budget constraint. Both undermine ex ante investment.

\footnotetext{
${ }^{29}$ See for instance Grossman and Hart (1986).
} 


\subsection{The Hold-Up Problem}

When he is an owner, the government may be eager to use information coming with ownership to better extract the manager's information rent. This might reduce the manager's incentives to undertake any specific investment: an hold-up problem. Note that this view of public ownership assumes a separation between the State as an owner and the State as a manager.

To illustrate this problem, I modify the basic model and add a moral hazard variable just as in Section 2.2. I remind the assumption made there: the cost parameter $\theta$ can be stochastically improved if the firm exerts a non-verifiable binary effort $(e=1$ at cost $\psi$ or $e=0$ at no cost). I characterize the agent's incentives to incur this investment under various governance structures.

Let us assume the following:

A4 The owner of an asset has a costless access to information on the production technology related to this asset. ${ }^{30}$

In our model, this means that the owner knows the cost parameter $\theta$.

Public Ownership: Consider first the case of a public firm. Recall that the government's commitment problem prevents it from signing binding contracts with the manager of the public firm.

Being the owner, the government observes $\theta$ ex post. Once this cost parameter is observed, the government and the manager bargain over the transfer and the output. Assuming that the manager has no bargaining power ex post, the government sets:

- a transfer that extracts all the manager's profit ex post, namely

$$
t^{*}(\theta)=\theta q^{*}(\theta)
$$

- a quantity $q^{*}(\theta)$ which is equal to the first-best defined by (5).

Anticipating this outcome which leaves him with zero rent, the manager of the public firm has no incentive to exert effort and chooses $e^{P u}=0$ (with the superscript $P u$ for

\footnotetext{
${ }^{30}$ Riordan (1990) focuses on vertical integration between a buyer and a seller and made this assumption in this context. See also Arrow (1975) for a model built on this assumption. Grossman and Hart (1986) argue instead that ownership does not change the information structure. It is not my purpose here to discuss these two alternative assumptions. I do not address here the (more) difficult question of why owners have more incentives to acquire information than non-owners. In the absence of any convincing theory linking property rights and information structures (see nevertheless Aghion and Tirole (1997) for a first step), I will take an agnostic approach here and simply analyze the consequences of one of these assumptions.
} 
public). The expected welfare under public ownership is thus:

$$
V^{P u}=\nu(0)\left(S\left(q^{*}(\underline{\theta})\right)-(1+\lambda) \underline{\theta} q^{*}(\underline{\theta})\right)+(1-\nu(0))\left(S\left(q^{*}(\bar{\theta})\right)-(1+\lambda) \bar{\theta} q^{*}(\bar{\theta})\right) .
$$

Private Ownership: Under private ownership, the government does not learn $\theta$ and the manager-owner of the firm has private information about $\theta$. Assuming again that the government has all bargaining power when offering the regulatory contract after the manager's learning of information, it offers an incentive mechanism which gives:

- an information rent $\underline{U}^{S B}=\Delta \theta q^{S B}(\bar{\theta}, \hat{e})$ to the efficient manager, and $\bar{U}^{S B}=0$ to the inefficient one.

- outputs $q^{\operatorname{Pr}}(\underline{\theta})=q^{*}(\underline{\theta})$ and $q^{\operatorname{Pr}}(\bar{\theta})=q^{S B}(\bar{\theta}, \hat{e})$ (with the superscript $\operatorname{Pr}$ for private) where:

$$
\frac{1}{1+\lambda} S^{\prime}\left(q^{S B}(\bar{\theta}, \hat{e})\right)=\bar{\theta}+\frac{\lambda}{1+\lambda} \frac{\nu(\hat{e})}{1-\nu(\hat{e})} \Delta \theta
$$

and $\hat{e}$ is the government's conjecture regarding the manager's choice of effort.

Anticipating that he will enjoy a rent only when $\underline{\theta}$ is realized, the manager exerts an effort if and only if the expected increase in rent exceeds the cost of effort:

$$
\Delta \nu \Delta \theta q^{S B}(\bar{\theta}, 1)>\psi
$$

where again $\Delta \nu=\nu(1)-\nu(0)>0$.

Privatization is thus a mechanism through which the State can commit to better reward the manager for his non-verifiable investment.

When condition (12) holds in equilibrium, ${ }^{31}$ the manager chooses $e^{P r}=1$ and the government adopts a restrictive policy in that the output $q^{S B}(\bar{\theta}, 1)$ is lower than $q^{S B}(\bar{\theta}, 0)$.

I can now compare the costs and benefits of privatization. Under private ownership, the expected welfare becomes:

$$
\begin{aligned}
V^{P r}=\nu(1) & \left(S\left(q^{*}(\underline{\theta})\right)-(1+\lambda) \underline{\theta} q^{*}(\underline{\theta})\right)+(1-\nu(1))\left(S\left(q^{S B}(\bar{\theta}, 1)\right)-(1+\lambda) \bar{\theta} q^{S B}(\bar{\theta}, 1)\right) \\
& -\lambda \nu(1) \Delta \theta q^{S B}(\bar{\theta}, 1)-(1+\lambda) \psi .
\end{aligned}
$$

Therefore, the benefit of shifting to private ownership is:

$$
\Delta V=V^{P r}-V^{P u}
$$

\footnotetext{
${ }^{31}$ When constraint (12) does not hold, there may either exist mixed strategy equilibria where the manager randomizes between investing or not or a pure strategy equilibrium where the manager does not invest at all.
} 


$$
\begin{aligned}
=\Delta \nu\{ & \left.S\left(q^{*}(\underline{\theta})\right)-(1+\lambda) \underline{\theta} q^{*}(\underline{\theta})-\left(S\left(q^{*}(\bar{\theta})\right)-(1+\lambda) \bar{\theta} q^{*}(\bar{\theta})\right)\right\}-\psi \\
+ & (1-\nu(1))[S(q)-(1+\lambda) \bar{\theta} q]_{q^{*}(\bar{\theta})}^{q^{S B}(\bar{\theta}, 1)}-\lambda \nu(1) \Delta \theta q^{S B}(\bar{\theta}, 1) .
\end{aligned}
$$

The first term in (13) captures the benefit of privatization, and the last two terms capture its costs. The first term is positive because effort has been assumed efficient under condition (6). This is the benefit of privatization. The second term is negative. It is the efficiency loss from moving to a second-best policy under asymmetric information. The last term is the social cost of the information rent left to the manager under private ownership. Note that the cost of asymmetric information increases when the cost of public funds $\lambda$ is greater. Somewhat paradoxically, the cost of privatization is thus greater when the States faces a harder budget constraint.

Appraisal: Some limitations of this model should be pointed out. ${ }^{32}$

- First, the hold-up problem also arises for private firms that fear changes in their regulatory environments. The result above assumes that this sort of hold-up is less pronounced, not that it is absent. ${ }^{33}$

- Second, with repeated interactions, the State and the firm may be able to sustain more cooperative outcomes. This can alleviate some the hold-up inefficiencies.

- Third, asymmetric information may reduce also the hold-up problem. By overinvesting, the manager may credibly signal that it has a high cost and secure greater subsidies.

- Fourth, the benefits of privatization are maximal in the model above because the firm is manager-owned. When there is a separation between ownership and control, agency conflicts inside the firm could affect the benefits or privatization.

\subsection{Repeated Relationships}

Sappington and Stiglitz (1987) suggest that "Government intervention is generally less costly under public ownership, but a promise not to intervene is more credible under private production". To analyze this issue, Gilbert and Newbery (1994) consider an infinitely repeated relationship between the State and the manager of a privatized regulated firm.

\footnotetext{
${ }^{32}$ The following critics are theoretically oriented. Greenwald (1984) argues that one way of avoiding the hold-up problem in practice is to impose a fair rate of return on investment through a law.

${ }^{33}$ Some authors have indeed stressed that the hold-up problem is also relevant for private regulated firms (see Section 3.2 below).
} 
They assume that the parameter $\theta$ is common knowledge. This parameter although observable is non-verifiable. No enforceable regulatory contract can thus be written between the State and the firm: an extreme form of incompleteness. ${ }^{34}$

I now consider a repeated relationship between the State and the firm. Assume that the State and the firm have the same discount factor $\delta$ which is related to the time between hearing periods. In a given period $i$, the manager chooses an investment level $k_{i}$ at cost $r k_{i}, r$ being the rental rate of capital. After investment, the marginal cost of production is reduced to $\theta-c\left(k_{i}\right)$ where $c^{\prime}>0, c^{\prime \prime}>0$. Finally, in each given period, the firm chooses its output. ${ }^{35}$

As before, I assume that the State cannot commit to reward the firm's investment because no contract can either be written. Only ex post bargaining is feasible and, at this stage, the State has all bargaining power. Suppose that the relationship were not repeated. In that case, the unique subgame perfect equilibrium of the (sequential moves) stage game is thus such that the firm neither invests nor produces $\left(k^{N}=q^{N}=0\right)$ and the State does not reward the firm $\left(t^{N}=0\right)$.

In an infinitely repeated relationship, more cooperative outcomes $(q, k, t)$ can be reached as subgame perfect equilibria. These equilibria are sustained with trigger strategies. Those strategies stipulate a return to the static Nash equilibrium of the stage game forever if anyone deviates from the strategies enforcing ${ }^{36}$ the vector $(q, k, t)$.

In any given period, the government compares the benefit of not paying the manager with the cost of forgoing the cooperative relationship. As shown in the Appendix, this incentive constraint can be written as:

$$
\delta S(q)-(1+\lambda) t+t-q(\theta-c(k))-r k \geq 0
$$

Similarly, the manager compares the benefit of neither investing nor producing with the cost of forgoing the cooperative relationship. This incentive constraint can be written as:

$$
t-q(\theta-c(k))-r k \geq 0
$$

To relax the government's incentive constraint (14), one must increase the opportunity cost of forgoing the relationship. This is obtained by raising the firm's output above the first-best level.

\footnotetext{
${ }^{34}$ Gilbert and Newbery (1994)'s model is quite specific (uncertain and inelastic demand, etc.) but its main thrust carries over to the setting considered below which better first with our unified framework.

${ }^{35}$ Note that investment affects directly marginal cost in this model contrary to what happens in Section 3.1 where it affects the distribution of those marginal costs. This simplifies the analysis because uncertainty will play no role in this section on repeated relationships.

${ }^{36}$ It should be stressed that this is the worst punishment strategy since that static subgame perfect equilibrium yields the minmax payoffs of both players. See Abreu (1988).
} 
When $\delta$ is not too large, ${ }^{37}$ the optimal regulatory outcome is such that both (14) and (15) are binding. The second-best policy is obtained as a solution to the system:

$$
\begin{gathered}
\frac{\delta}{1+\lambda} S\left(q^{S B}(\theta)\right)=q^{S B}(\theta)\left(\theta-c\left(k^{S B}(\theta)\right)\right)+r k^{S B}(\theta), \\
q^{S B}(\theta) c^{\prime}\left(k^{S B}(\theta)\right)=r,
\end{gathered}
$$

Increasing output spreads the benefits of investing over a greater output base. This reduces the benefits of investing and investment is reduced below the first-best.

This analysis shows that, even in the extreme case in which enforceable contracts cannot be enforced, a government can follow a self-enforceable equilibrium strategy which nevertheless offers enough rewards for investment.

If one thinks of the firm as being privatized but regulated, the government's concerns for the future of its relationship with the private sector is enough to ensure that private investments are not expropriated. However, the first-best outcome is still not reached.

Appraisal: The assumption that no enforceable regulatory contract can be signed is of course an extreme one. In all but the least developed countries, regulatory contracts can be at least partially enforced. The analysis above should be seen as applying to the residually non-enforceable dimensions of explicit contracts. It shows that these dimensions can be controlled, at least partially, through implicit contracts between the State and the private sector.

The model does not draw an explicit distinction between private and public firms and, in principle, applies equally to both types of firms. Both types of firms are indeed subject to the same hold-up problem, the public firm vis-à-vis the State as an owner, the private one vis-à-vis the State as a regulator. To restore a difference between public and private ownership, the model should be expanded or, at least, reinterpreted. One approach would be to distinguish ownership structures in terms of the information they give to third-parties. Under private ownership, a deviation by the government may be observed by the management of other regulated firms, while this may not be true under public ownership. In that case, deviating may be more costly under private than public ownership as it affects negatively the government's credibility vis-à-vis other private firms. This suggests that defining a self-enforcing credible regulation is somewhat easier with private rather than with public firms in settings where multiple private firms are regulated.

The model discussed in this section describes an environment with an extremely weak government/regulator, unable to commit to any regulatory mechanism. This setting is more akin to the institutional environments of some developing countries than the regulatory settings of developed countries. Such unstable environments are favorable to hold-up.

\footnotetext{
${ }^{37}$ The case $\delta$ close to one is discussed in the Appendix.
} 
Underinvestments in specific assets and infrastructures may be an impediment to development. ${ }^{38}$ A greater instability in the environment can be captured by a decreasing discount factor of the players which induces greater inefficiencies.

\subsection{Bargaining under Asymmetric Information}

Besanko and Spulber (1992) show how asymmetric information can sometimes alleviate the hold-up problem, at least partially. They develop a model in which investment has a signalling value. Over-investment can be used by the firm to signal its inefficiency and extract more out of the bargaining process taking place with the State.

In the Appendix, I sketch how our basic model can be extended in that direction. Because transfers are determined in an ex post bargaining which shares the gains from trade between the firm and the State, the firm receives a greater transfer when its costs are high. This clearly creates a problem when the firm has private information on costs. Indeed, if an inefficient firm does not separate itself from an efficient one, the latter would invest and produce the same amounts inducing the regulator to wrongly believe that the average efficiency of the firm is higher than it truly is. To convince the regulator that its technology is inefficient and secure greater transfers, an inefficient firm must excessively invest to reduce its marginal cost as a credible signal of its inefficiency. This reduces hold-up but comes at the cost of increasing excessively the output of an inefficient firm.

Appraisal: Again, this model captures the relationship between the State and the firm in an incomplete contract environment characterized by a rather weak government without any commitment ability. Although the model proposes a possible response to the hold-up by the State as a regulator, it does not draw a clear distinction between public and private firms: it assumes a priori that the hold-up problem arises only with private firms. Note that this assumption is the opposite to that underlying the model of Section 3.1.

\subsection{Separation Between Ownership and Control}

The model in Section 3.1 assumes away the governance issue internal to private firms. To discuss this issue, one must introduce shareholders of the private firms as separate from its management. Schmidt (1996) pursues this line of research. He makes two other assumptions in addition to A4. Otherwise the model is as in Section 3.1.

A5 In a private firm, the shareholders and the manager have different preferences.

To model this, I consider an all-equity firm for simplicity. Shareholders are only

\footnotetext{
${ }^{38} \mathrm{An}$ example of such unstable developing countries is China over its transition to market. See Che and Qian (1988) for a static model of unsecure property rights.
} 
interested in the firm's profits $\pi=t-\theta q$ net of the manager's wage $y$. In contrast, the manager enjoys non-monetary private benefits. Assume that those non-monetary benefits $u(q)$ increase with output $\left(u^{\prime}>0\right.$ and $\left.u^{\prime \prime}<0\right)$. For instance, as output increases, the manager's reputation or visibility might improve, or he may enjoy more perks. The manager's preferences are thus now given by $U=u(q)+y$ where $y$ is his wage.

A6 Shareholders have no control of the manager's investment. ${ }^{39}$

- Public Ownership: In a public firm, the State cannot refrain from implementing an efficient outcome ex post (once $\theta$ is realized). Thus, the transfer and output are respectively given by (10) and (5). ${ }^{40}$ The manager will exert effort if and only if

$$
\Delta \nu\left(u\left(q^{*}(\underline{\theta})\right)-u\left(q^{*}(\bar{\theta})\right)\right) \geq \psi
$$

The left-hand side of (18) represents the manager's incremental gains from raising the probability that the firm is efficient. The right-hand side is the cost of that investment. Notice that (18) is easier to satisfy when the inefficient firm's output is smaller. It is worth stressing that the manager's private benefits provide incentives to invest in that model. This is in contrast with Section 3.1 where the manager's rent in a private firm played this role as one can see from comparing (12) with (18).

- Private Ownership: Under private ownership, shareholders are informed, the State is not. The State contracts directly with informed shareholders under asymmetric information. Shareholders themselves contract with the manager under symmetric information. Asymmetric information between the State and the shareholders implies a standard rentefficiency trade-off, which results as usual in downward distortions of the firm's output. The analysis is basically the same as in Section 3.1. In particular, an inefficient firm no longer produces the first-best output $q^{*}(\bar{\theta})$ but instead $q^{S B}(\bar{\theta}, \hat{e})$ given by $(11)$, where $\hat{e}$ denotes the conjecture of the State and shareholders on the manager's effort.

Consider now the contract between the shareholders and the manager. Because contracting takes place under symmetric information, the shareholders extract the manager's monetary rent. However, in contrast to Section 3.1, the manager's incentives are not driven by his rent but by the non-monetary private benefits. An equilibrium with a high effort is thus obtained when

$$
\Delta \nu\left(u\left(q^{*}(\underline{\theta})\right)-u\left(q^{S B}(\bar{\theta}, 1)\right)\right) \geq \psi .
$$

Note that (19) is easier to satisfy than (18) because $q^{S B}(\bar{\theta}, 1)<q^{*}(\bar{\theta})$. Therefore, the manager's incentives to invest are increased under private ownership. The friction in

\footnotetext{
${ }^{39}$ Note that this assumption conflicts somewhat with $\mathrm{A} 4$. Owners have access to information on an exogenous technological parameter but not to information related to the endogenous choice of investment.

${ }^{40}$ Note that the non-monetary benefits of production of the manager are assumed to be negligible and not taken into account in the expression of social welfare.
} 
contracting due to asymmetric information between the State and the shareholders leads incidentally to increase effort.

The key difference with Section 3.1 is that these incentives to invest no longer arise because the manager enjoys the information rent associated with ownership (in that model, shareholders do). These incentives arise from the fact that perks, reputation and private benefits are positively correlated with the firm's output and these benefits may decrease under asymmetric information if the manager does not invest sufficiently.

Appraisal: Because this theory of privatization relies on the notion of private benefits, one would like to endogenize them from more fundamental assumptions. As in Section 3.1 for example, private benefits could stand for information rents. Such an approach however may entail some contradictions. In a private firm, the manager does not own the asset and may therefore, given assumption A4, share his knowledge of the technology with shareholders. Private ownership would shield the manager from the State's opportunism but expose him to that of shareholders, leading to the same underinvestment problem. To avoid this outcome, one needs to relax assumption A4 and assume that ownership does not give full information to the owners. This of course fosters incentives under private ownership but, by the same token, also fosters incentives under public ownership. This complicates the comparison between the two governance structures.

On the other hand, if one believes that private benefits do not stem from information but for instance from the manager's reputational concerns, modelling these would be useful. Indeed, one would need to check that the form of private benefits is the same under public and private ownership. ${ }^{41}$

Much work remains to be done about the relationship between shareholders and managers in a regulated private firm. As a first step, Faure-Grimaud (2002) endogenizes the information structure and stresses the role of stock price information as a substitute for the regulator's own monitoring. Under some circumstances, it is shown that public listing of the firm improves the manager's ex ante effort.

\subsection{The Soft-Budget Constraint of Public Firms}

To illustrate the soft budget constraint problem in public firms, one needs a model with limited commitment by the government. The basic assumption is now the following.

A7 As an owner, the State cannot refrain from using public funds if it is ex post optimal

\footnotetext{
${ }^{41}$ For instance, it could be that those reputation concerns are quite different for a manager in the public sector and a manager in the private sector. In France, it is clear that the labor market for CEOs of public firms (civil servants coming out of the so-called Corps des Mines and Corps des Ponts) does not coincide with that for CEOs of the private sector, which is more open.
} 
to do so. Private owners are subject to a harder budget constraint.

We examine the consequences of banning regulatory transfers between the State and a private regulated firm. Our goal here is to show that hardening the firm's budget constraint ex post may foster ex ante incentives to undertake firm-specific investment.

More precisely, suppose that, by incurring ex ante a non-verifiable although observable investment $I$, the manager reduces the firm's fixed cost $K_{0}$ by an amount $d(I)\left(d^{\prime}>\right.$ $\left.0, d^{\prime \prime}>0\right)$.

Also assume that the firm produces a quantity $q$ at cost $\theta q+K_{0}-d(I)$ and sells at price $P(q)$ so that the net surplus is $S(q)-P(q) q$.

- Public Ownership: Ex post, once the firm's investment has been sunk, the State can offer monetary transfers $\{\underline{t}, \bar{t}\}$ in an incentive compatible way. Those transfers reimburse the firm's fixed cost without inducing new distortions on output. The optimal regulation can be shown (see the Appendix) to implement outputs $\left(q^{*}(\underline{\theta}), q^{P u}(\bar{\theta})\right)$ such that:

$$
\begin{aligned}
P\left(q^{*}(\underline{\theta})\right)-\underline{\theta} & =-\frac{\lambda}{1+\lambda} P^{\prime}\left(q^{*}(\underline{\theta})\right) q^{*}(\underline{\theta}), \\
P\left(q^{P u}(\bar{\theta})\right)-\left(\bar{\theta}+\frac{\nu}{1-\nu} \frac{\lambda}{1+\lambda} \Delta \theta\right) & =-\frac{\lambda}{1+\lambda} P^{\prime}\left(q^{P u}(\bar{\theta})\right) q^{P u}(\bar{\theta}) .
\end{aligned}
$$

These are the usual Ramsey formulae modified to take into account that costs have to be replaced by virtual costs under asymmetric information.

Because the State-regulator cannot refrain from using transfers to cover the firm's fixed-cost, the manager's information rent does not depend of the level of the fixed-cost: $U^{P u}(\underline{\theta})=\Delta \theta q^{P u}(\bar{\theta}), U^{P u}(\bar{\theta})=0$. In other words, when the State cannot refrain from using transfers after an investment, it cannot reward the firm for its investment. As a result, the firm does not invest: $I^{P u}=0$.

- Private Ownership: Assume now that the firm is private and does not receive transfers from the State. Regulation only stipulates the firm's output to ensure that it breaks even. The absence of monetary transfers makes it impossible to screen different types of firm which both get to produce the same output $q^{\operatorname{Pr}}(I)$. This output is such that the inefficient firm breaks even

$$
\left(P\left(q^{P r}\right)-\bar{\theta}\right) q^{P r}(I)=K_{0}-d(I) .
$$

The efficient firm gets then an information rent

$$
\underline{U}^{P r}=\Delta \theta q^{P r}(I)
$$

Note that the output of a private firm increases now with its investment $\left(q^{\operatorname{Pr}}(I)\right.$ increases with $I$ ). This makes the firm internalize at least partly the impact of its ex ante 
investment. This investment is now set so that:

$$
\nu \Delta \theta \frac{d q^{P r}}{d I}\left(I^{P r}\right)=1
$$

When investment has a sufficiently large social value, private ownership dominates. Intuitively, under a hard-budget constraint, the manager has strong incentives to reduce the fixed cost to increase output and his expected information rent.

Appraisal: This theory relies on the assumptions that the State finds it easier to commit as a regulator (who does not use transfers) than as an owner. This assumption, while not endogenized, may seem reasonable. Indeed, it is likely easier to enforce a Law banning regulatory transfers than to forbid manipulations of the Treasury. This has led several authors to take an extreme version of the model sketched above and view private firms as being fully unregulated. ${ }^{42}$ In that case, a trade-off arises between imperfect commitment under public control and market power under private ownership. This approach reintroduces some form of commitment by assuming that the State can commit not to regulate private firms.

Finally, the model predicts a lower financial burden on the State under private ownership than under public ownership. Hence, States which have strong laws against budget deficits and restrictions on borrowing ${ }^{43}$ are likely to privatize more; a fact which has received some empirical support. ${ }^{44}$

\section{Limits to State Control}

\subsection{Exogenous Governance}

Laffont and Tirole (1993, Chapter 17) argue that the fundamental difference between a private and a public firm lies in the fact that different stakeholders exert internal control on that firm's activities (for instance decide on the manager's incentive scheme, on which inputs should be used, etc...). In a public firm, the State exerts both internal and external control (regulate price, outputs and investments, etc...). In a private but possibly regulated firm, internal control is exercised by shareholders. Therefore, the manager has now two principals, the State-regulator and the shareholders who both influence the firm's decisions in different directions.

That split of control has an allocative cost that must be compared with the benefit of privatization. The benefit stems from the fact that the manager's investment can no

\footnotetext{
${ }^{42}$ See for instance Segal (1998) and Auriol and Picard (2004).

${ }^{43}$ California is an example in order.

${ }^{44}$ See Bortolotti and Siniscalco (2003) and Lopez-Silanes, Shleifer and Vishny (1997).
} 
longer be appropriated by the State. If the firm is public, the State can reallocate those investments towards alternative uses which are less rewarding for the manager but which may have a greater social value. ${ }^{45}$ Instead, private owners do not find such alternative uses for the investment so that the manager's investment is better protected from the threat of hold-up. ${ }^{46}$

Contrary to the Riordan-Schmidt model, the Laffont and Tirole's framework does not equate ownership with access to information. Instead, A4 is now replaced by:

A8 State ownership allows the State to control communication channels between the firm's manager and outsiders.

A8 means that ownership gives owners the residual right to limit the contracts that the manager can sign. In a public firm, that assumption implies that all contracts are cooperatively designed. In a private firm, contracting is instead less centralized since both the State-regulator and the firm owners are eager to elicit information from the manager.

Let us compare the two ownership structures.

- Public Ownership: In a public firm, the State redeploys the manager's investment towards an alternative use yielding a benefit $D^{\prime}>I .{ }^{47}$ Anticipating this expropriation, the manager does not invest and the optimal contract implements the outputs $q^{*}(\underline{\theta})$ and $q^{S B}(\bar{\theta})$. The manager gets a rent when the firm is efficient, $U^{S B}(\underline{\theta})=\Delta \theta \bar{q}^{S B}(\bar{\theta})$. Finally, expected welfare is thus:

$V^{P u}=\nu\left(S\left(q^{*}(\underline{\theta})\right)-(1+\lambda) \underline{\theta} q^{*}(\underline{\theta})\right)+(1-\nu)\left(S\left(q^{S B}(\bar{\theta})\right)-(1+\lambda) \bar{\theta} q^{S B}(\bar{\theta})\right)-\nu \lambda \Delta \theta q^{S B}(\bar{\theta})$.

- Private Ownership: Shareholders cannot redeploy the manager's investment towards alternative uses. Internal use yields a benefit $D>I$ to the manager. Denote $\Delta=D-I$ the net benefit of that investment.

As owners, the shareholders design the manager's incentive scheme, or equivalently, the dividend scheme $z(q)$, as a function of the realized output. The shareholders' benefits from the venture can thus be written as

$$
\Pi=z
$$

The manager's utility, net of the dividends redistributed to shareholders and the ben-

\footnotetext{
${ }^{45}$ This may include, for instance, granting access to the infrastructure to competitors or to the general public.

${ }^{46}$ This difference in the opportunities of the State and of private owners to reallocate assets towards alternative uses may seem extreme. However, it is a simple way of capturing the State's greater tendency to expropriate the manager because of political pressures or because of the desire to please some constituencies by reallocating assets.

${ }^{47}$ Notice that this investment does not affect the probability that the firm is efficient contrary to the Riordan-Schmidt model.
} 
efits of investment, is now

$$
U=t-z-\theta q+\Delta
$$

The State maximizes social welfare:

$$
V=S(q)-(1+\lambda) t+U+\Pi
$$

We assume that the regulator and the shareholders make simultaneously and noncooperatively their contractual offers, namely $t(q)$ and $z(q)$, to the manager. Such a simultaneous moves game admits multiple Nash equilibria since different nonlinear schedules may sustain the same equilibrium quantities and transfers and different equilibrium outputs may also be reached.

The equilibrium output values must satisfy the following of aggregate incentive constraints (see the Appendix):

$$
\begin{gathered}
S(\underline{q})-(1+\lambda) \underline{\theta} \underline{q} \geq S(\bar{q})-(1+\lambda) \underline{\theta} \bar{q}, \\
S(\bar{q})-(1+\lambda) \bar{\theta} \bar{q}+(1+\lambda) \Delta-\frac{2 \nu \lambda}{1-\nu} \Delta \theta \bar{q} \geq 0 .
\end{gathered}
$$

Consider the perspective of a social planner maximizing the same objective as in the case of a public firm, and selecting the best equilibrium from a social welfare viewpoint within this whole set of allocations implementable through a common agency game. Clearly, this equilibrium entails no allocative distortion for an efficient firm and $q^{\operatorname{Pr}}(\underline{\theta})=q^{*}(\underline{\theta})$. In general, the inefficient firm's output is distorted to satisfy the no veto constraint (25) which stipulates that neither principal wants to veto production by the least efficient firm. ${ }^{48}$ Denoting by $\mu(1-\nu)$ the positive multiplier of that constraint, we must have

$$
\frac{1}{1+\lambda} S^{\prime}\left(\bar{q}^{\operatorname{Pr}}(\bar{\theta})\right)=\bar{\theta}+\frac{\lambda(1+2 \mu)}{(1+\lambda)(1+\mu)} \frac{\nu}{1-\nu} \Delta \theta
$$

Distortions are increased under private ownership. To ensure that the principals are not willing to veto production by the inefficient firm, the corresponding output must be reduced so that the information rent of the efficient firm is not too large when both types produce. The private firm (when inefficient) is under a harder budget constraint since it requires the agreement of both the State and its shareholders to produce. Therefore, private ownership entails strong inefficiencies even though it better protects the manager's investment.

\footnotetext{
${ }^{48}$ To be sure that (25) is binding in that optimization, it must be that

$$
\frac{1}{1+\lambda} S\left(q^{S B}(\bar{\theta})\right)-\bar{\theta} q^{S B}(\bar{\theta})+\Delta-\frac{\lambda}{1+\lambda} \frac{2 \nu}{1-\nu} \Delta \theta q^{S B}(\bar{\theta})<0 .
$$
}

a condition that will be assumed to hold in the discussion below. 
Private ownership is more likely to dominate when $\Delta$, the manager's benefits of having his investments not redeployed, is large enough. Constraint (25) is indeed less of an issue when the manager enjoys greater private benefits (increasing $\Delta$ relaxes (25)). The manager can be implicitly rewarded with these benefits and the incentives of either principal to cut transfers and subsidies to the firm are weaker than in the absence of those implicit rewards.

Appraisal: This multiprincipal model is attractive because it formalizes the lack of internal control by the State under private ownership and derives the corresponding transaction costs in terms of extra output distortions. However, it has the seemingly unappealing feature that private firms have lower power incentives (lower output) than public firms. This result should be interpreted with a word of caution given the conventional wisdom that private ownership increases incentives. Indeed, in this model, privatization increases incentives on the dimensions of the manager's activities which are non-verifiable, i..e., the manger's investment is better protected under private ownership.

The model could also be extended to allow some complementarity between investment and cost reduction. For instance, the manager's investment in asset maintenance may allow to reduce operating costs. In that case, if privatization increases incentives for long-term investment, it might also induce more cost reduction and thus increase output.

\subsection{Endogenous Governance}

The separation between ownership and control in the privatized firm was assumed and not explained in Section 4.1. Lewis and Sappington (1995) consider a model close to that of Section 2.1. to endogenize the presence of shareholders (different from the manager) and the type of claims they hold. This theory relies on the degree of risk-aversion of the State. Risk-aversion can be viewed as a proxy for an increasing and convex cost of raising money through distortionary taxation.

- Public Ownership: In the absence of any outside financiers, the risk-averse State can no longer use a "sell-out" contract under ex post contracting. ${ }^{49}$ Instead, only partial insurance can be achieved by distorting allocations away from the first-best level. To formalize this point, I modify the basic model with imperfect commitment and adapt it

\footnotetext{
${ }^{49}$ I already stressed in the discussion of the basic model that, under ex ante contracting, the "sell-out" contract performs quite well. By making the risk-neutral manager residual claimant for the returns on the assets, the risk-averse State achieves the first-best and is fully insured. Of course, that outcome can no longer be achieved under ex post contracting. The State's lack of commitment replaces the ex ante participation constraint of the manager by ex post ones. That assumption is akin to assuming that the manager is infinitely risk-averse.
} 
to the case of a risk-averse principal. ${ }^{50}$

In the optimal contract, only the efficient firm gets a positive rent $U^{P u}(\underline{\theta})=\Delta \theta q^{P u}(\bar{\theta})$ where the inefficient firm's output is downward distorted but less so than under riskneutrality, $q^{P u}(\bar{\theta})>q^{S B}(\bar{\theta})$. These distortions are needed to reduce the costly ex post information rent of an efficient firm. However, the State's demand for insurance makes it reluctant to distort the output of the inefficient firm, so that social welfare does not depend too much on whether the firm is efficient or not.

- Private Ownership: Access to capital markets can help reconcile the conflicting objectives of extracting the firm's rent and giving insurance to the State. Outside investors may be better diversified and thus willing to insure the State (this may be particularly relevant for small local governments). I assume that a capital market exists with perfectly competitive risk-neutral investors.

Denote by $\bar{z}$ and $\underline{z}$ the investors' return in states $\bar{\theta}$ and $\underline{\theta}$. The manager's utility is $U=t-z-\theta q$ after having redistributed dividends. Competitive investors break even when:

$$
\nu \underline{z}+(1-\nu) \bar{z}=0
$$

It can be shown (see the Appendix) that the investors' claim resembles equity, i.e., $\underline{z}^{P r}>0>\bar{z}^{P r}$. Given that the State can off load risk onto investors, we are back to the standard model of Section 2.3 without full commitment and the strongly distorted output $q^{S B}(\bar{\theta})$ is implemented. Again, under private ownership, this result can be interpreted as the firm being subject to a harder budget constraint.

Appraisal: In this model, outside equity financing is always optimal. Following Section 4.1, a cost of outside financing could be introduced by explicitly modelling the noncoordination between the State-regulator and shareholders when they contract with the manager. This would yield an interesting trade-off between the benefits and the costs of introducing outside financiers.

Perotti (1995) proposes another theory of partial privatization in a model with a riskaverse State. He observes that sales of private firms are generally gradual and that the government retains large stakes of the privatized firm even after having relinquished control rights to equityholders. Partial sales signal to the capital market that the government is committed to privatization and will not exert ex post pressures on the firm. In a model of delegated management, Martimort and Sand-Zantman (2004) show that an informed risk-averse State may choose to offer low power incentive contracts and bear much of the operating risks to convince the firm of the high quality of the assets. Under some form of incomplete contracting, this signalling argument calls for restricting the scope of

\footnotetext{
${ }^{50}$ See Laffont and Martimort (2002, Chapter 2).
} 
privatization and keeping assets under State ownership.

\section{Non-Benevolent Political Principals}

I now discuss the pros and cons of privatization when political principals are not social welfare maximizers but instead are biased in favor of specific interest groups, be they industry owners or consumers. The general argument here is that privatization can be a safeguard against the opportunistic behavior of political principals. From a social welfare perspective, privatization is a substitute for the missing incentives of political principals, or for some imperfections in the process of delegating regulatory powers to them when they are not social welfare maximizers.

\subsection{A Social Benefit of Reducing State Control}

Following Shapiro and Willig (1990), consider a biased political principal who favors excessively the industry he regulates. His objective function can now be written as

$$
V=S(q)-(1+\lambda) t+\beta U
$$

where $\beta>1$ is the weight given to the firm in the political decision-maker's objective. I also assume that $\beta<1+\lambda$, so that the firm's information rent remains costly.

The government is nevertheless captured by the industry and leaves it too much rent (since $\beta>1$ ). This bias may materialize under the form of excessive subsidies, workers wages above the efficiency wages, or excessive employment. ${ }^{51}$

A key point however is that the bias is only relevant when ex ante contracting is not feasible. Otherwise, even a biased principal would be eager to extract all ex ante rent of the industry and the full information first-best outputs would still be implemented. Differences in governance structures only matter under asymmetric information at the time of contracting. To stress that point, I state that lack of commitment as a fundamental assumption of the analysis.

A9 Partial Commitment: Only ex post contracting is feasible.

- Public Ownership: The only difference with the social planner's solution comes from the distortion of the inefficient firm's output. We have $q^{P u}(\bar{\theta})>q^{S B}(\bar{\theta})$ where

$$
\frac{1}{1+\lambda} S^{\prime}\left(q^{P u}(\bar{\theta})\right)=\bar{\theta}+\left(1-\frac{\beta}{1+\lambda}\right) \frac{\nu}{1-\nu} \Delta \theta
$$

\footnotetext{
${ }^{51}$ Lopez-de-Silanes, Shleifer and Vishny (1997) reported that wages in the public sector are 10 to 20 percent above their value for similar jobs in the private sector. See also Savas (1987).
} 
Note that $q^{P u}(\bar{\theta})$ increases with $\beta$. In particular, for $\beta<1$, this distortion is lower than with a benevolent principal since the manager's rent is less costly for a biased one.

- Private Ownership: Following Schmidt (1996), shareholders are interested only in the firm's profit net of the manager's wage. Shareholders act as uninformed intermediaries between the State-regulator and the informed manager. This lengthens the hierarchy between the State and the firm's manager under private ownership. Since both the State and the shareholders are uninformed about the firm's technology, there is an incentive problem at each tier of this hierarchy. Instead, this incentive problem is assumed not to exist under public ownership. The implicit assumption here is again that the State does not have the internal control of the firm and can neither observe nor regulate how dividends are distributed in a private firm. Instead, within a public firm, any relationship between the manager and intermediaries (for instance, a public board of directors or the senior management of the firm) can be observed and controlled by the State. As in Schmidt (1996), public ownership endows the State with information. However, as in Laffont and Tirole (1993), this is not information on technology which is relevant here but on the firm's contractual relationships.

To analyze the issue of nested contracting between the State and shareholders, on the one hand, and between shareholders and the manager on the other hand, I use a model of delegation close to those developed in Faure-Grimaud and Martimort (2001) and Martimort (1999) (see the Appendix for details).

The solution entails a distortion for the inefficient firm only, that exceeds that under public ownership. That is, $q^{P r}(\bar{\theta})<q^{P u}(\bar{\theta})$ where $q^{P u}(\bar{\theta})$ solves:

$$
\frac{1}{1+\lambda} S^{\prime}\left(q^{P u}(\bar{\theta})\right)=\bar{\theta}+\frac{\nu}{(1-\nu)(1+\lambda)}\left(1+\lambda-\beta+\frac{1}{1-\nu}\right) \Delta \theta .
$$

When $\beta \leq 1+\frac{1}{1-\nu}, q^{P r}(\bar{\theta})$ remains above $q^{S B}(\theta)$, the socially optimal output, but is now below $q^{P u}(\bar{\theta})$. The introduction of uninformed shareholders, between the Stateregulator and the manager reduces the biased regulator's tendency to increase excessively the firm's output. Therefore, it improves social welfare.

Uninformed shareholders may want to shut-down the firm if they view the rent of the manager as too costly. To insure that shareholders are not willing to exercise this veto right, the manager's rent must be small enough and output sufficiently distorted downwards. Giving this veto right to shareholders hardens the firm's budget constraint and therefore acts as a safeguard against the political principal's incentives to inflate the firm's subsidy.

Appraisal: The basic premise that privatization can reduce the opportunistic behavior of politicians seems reasonable. However, privatization seems an imperfect tool to adjust 
the behavior of politicians compard to more explicit mechanisms such as elections.

Also, if the point is to reduce the manager's rents and the benefits that a nonbenevolent politician can appropriate, it is not obvious that introducing outside shareholders may be the best way to proceed. Indeed, separation of powers within the government could achieve the same outcome by introducing some explicit competition among agencies which would lead to an inefficiently low production. ${ }^{52}$

Moreover, the extra distortion under private contracting may be undesirable if the politician is biased against the firm $(\beta<1)$. Pro-consumers politicians are already too eager to extract the firm's rent. Hardening the latter budget's constraint through privatization would further reduce welfare. According to this theory, one should thus expect privatization when the State is biased in favor of the firm.

An alternative route is to think of the process of privatization itself as being driven by non-benevolent governments. ${ }^{53}$ This is the line of research followed by Shleifer and Vishny (1994), Bennedsen (2000) in incomplete contracting environments and Laffont (2005, Chapter 3) in an agency model where the principal derives private benefits from ownership but can also use the proceeds from privatization for private uses. It is shown that the private gains from keeping the firm public can exceed the appropriation of rent under privatization. The difficulty of such approaches is that, although the government is biased under both ownership structures, the type of bias depends on the ownership structure.

\subsection{Partisan Politics}

The bias of political principals need not be rooted in corruption Elected politicians may favor constituencies which give them political support. Politicians may thus have either a pro-firm or a pro-consumers bias. Alternation of these biased political principals in power exposes the firm to regulatory risk. ${ }^{54}$ This risk will depend on the ownership structure of the firm and will thus affect differently expected welfare depending on the governance mode.

Laffont (1996) shows that the ownership structure of the firm can be used to increase

\footnotetext{
${ }^{52}$ See Martimort (1996) and Laffont and Martimort (1999) for some related models showing that structuring regulatory intervention through multiprincipals helps to fight regulatory capture.

${ }^{53} \mathrm{In}$ an account of the received theory of privatization and its usefulness for developing countries, Laffont (2005, p.69) stated that "The above incomplete information and incomplete contracting arguments must certainly be combined with a more cynical view of government".

${ }^{54}$ It is a quite spread view that liberal rightist governments favor privatization for ideological reasons. In France, we have seen over the 80's a balance between nationalizations led by the Mauroy socialist government and two waves of privatization led by the rightist governments of Chirac (1986) and Balladur (1991): a typical case of partisan politics.
} 
expected welfare when partisan political principals alternate randomly. Consider two political principals $P_{1}$ and $P_{2}$ representing different constituencies (firms and consumers) alternating in power. The pro-firm principal defends shareholders. If there is a fraction $\alpha$ of those shareholders in the population principal $P_{1}$ maximizes:

$$
V_{1}=\alpha(S(q)-(1+\lambda) t)+U
$$

Assume $\frac{1}{\alpha}<1+\lambda$ so that the firm's information rent is costly even for $P_{1}$.

Instead, principal $P_{2}$ 's objective is:

$$
V_{2}=(1-\alpha)(S(q)-(1+\lambda) t)
$$

The political game is simple. The fraction $\alpha$ is equiprobably distributed on $\left\{\frac{1}{2}-\beta, \frac{1}{2}+\beta\right\}$. Hence, under simple majority rule, $P_{1}$ and $P_{2}$ are equally likely to be elected. The parameter $\beta$ can be viewed as a measure of the degree of polarization of the society.

The important assumption that drives the results is the following.

A10 Taxes are non-discriminatory: Shareholders and non-shareholders pay the same per capita taxes to finance the regulated firm.

If discriminatory taxes were feasible, the majority of voters could extract all the surplus from the minority and would, in the end, implement policies maximizing social welfare. In that case, whether owners or non-owners get in power would have no consequence on the optimal regulatory policy. There would be no politically induced fluctuations in outputs and information rents and, therefore, no effect of privatization on these fluctuations. Put differently, the ownership structure is thus a rough substitute for some missing redistributive instruments.

Now, assume that A10 holds. First, consider the case where $P_{1}$ holds office (i.e., $\alpha=\frac{1}{2}+\beta$ ). In that case, shareholders are in power, and the optimal contract is the same under public and private ownership. Only the inefficient firm's output is downwards distorted by the pro-firm political principal. The distortion is given by:

$$
\frac{1}{1+\lambda} S^{\prime}\left(q_{1}(\bar{\theta})\right)=\bar{\theta}+\frac{\nu}{1-\nu}\left(1-\frac{1}{\left(\frac{1}{2}+\beta\right)(1+\lambda)}\right) \Delta \theta .
$$

Now consider the case where $P_{2}$ is in power $\left(1-\alpha=\frac{1}{2}+\beta\right)$. Public and private ownership have now strong allocative and distributive consequences.

- Public Ownership: When the firm is public, consumers enjoy the rent of that firm. The firm has a weight equal to one in $P_{2}$ 's objective:

$$
V_{2}^{P u}=(1-\alpha)(S(q)-(1+\lambda) t)+U .
$$


Assume that $\frac{1}{1-\alpha}<1+\lambda$ so that the firm's information rent is still costly for $P_{2}$. The output $q_{2}^{P u}(\bar{\theta})$ is again given by $(30)$.

- Private Ownership: If the firm is private, the consumers no longer enjoy its information rent. The optimal contract implies an excessive downward distortion in the inefficient firm's output since $P_{2}$ does not internalize the firm's rent in his objective:

$$
\frac{1}{1+\lambda} S^{\prime}\left(q_{2}^{P r}(\bar{\theta})\right)=\bar{\theta}+\frac{\nu}{1-\nu} \Delta \theta
$$

- Under public ownership, the output is always given by (30). Since $\frac{1}{2}+\beta<1$, this output exceeds the socially optimal level $q^{S B}(\bar{\theta})$.

- Under private ownership, the output fluctuates. Under the pro-firm government, there is not enough distortion and $q_{1}(\bar{\theta})$ is implemented. Under the pro-consumer government, the distortion is instead excessive.

The decision whether to privatize amounts to a choice between always giving up an excessive rent to the firm under public ownership or having fluctuations of that rent around the socially optimal level under private ownership.

Assuming that $S(\cdot)$ is quadratic $\left(S(q)=\mu q-\frac{\lambda q^{2}}{2}\right.$ for some pair $(\lambda, \mu)$ such that outputs remain always positive), it is easy to check that privatization is socially preferable if and only if the average of the distortion is closer to the socially optimal one than under public ownership, i.e., if and only if:

$$
\frac{\lambda}{1+\lambda} \leq \frac{1}{2}\left\{1+1-\frac{1}{\left(\frac{1}{2}+\beta\right)(1+\lambda)}\right\}=1-\frac{1}{(1+2 \beta)(1+\lambda)}
$$

which always holds when $\beta \geq 0$. In this simple example, privatization always dominates. ${ }^{55}$

Appraisal: As discussed above, taking a social welfare perspective to assess the costs and benefits of privatization may not be warranted. Indeed, the privatization decision and process are themselves undertaken by biased politicans. Moreover, privatization can have long-lasting effects. ${ }^{56}$ In some institutional contexts (e.g., developed countries), property rights are sufficiently secured so that privatization is unlikely to be overturned rapidly and may therefore constrain future governments. In that respect, privatization may be a way of protecting current majority against being tomorrow's minority. ${ }^{57}$

\footnotetext{
${ }^{55}$ Other functional forms may reverse this result.

${ }^{56}$ See Faure-Grimaud and Martimort (2003) for a model of political choice with long-lasting consequences in the framework of partisan politic models of regulation.

${ }^{57}$ Biais and Perotti (2002) developed such commitment models although not in an agency context.
} 


\section{Incentives within the Bureaucracy}

Some authors (Wilson (1989) and Dixit (1996) among others) have argued that a public bureaucracy tends to have badly defined and even sometimes conflicting missions ${ }^{58}$ because they must respond to several masters (several legislative bodies, several ministries, etc.). Instead (the argument goes as follows), in private organizations, bureaucrats are more focused because the only objective of those organizations is profit maximization. It is certainly true that the separation of powers rooted in the design of most constitutions puts the manager of public firms at a nexus of many influences, be they implicit (i.e., coming from various Committees and Subcommittes in Congress) or more explicit (for instance the fact that those managers may be appointed by the Executive branch and then have to follow laws enacted by the Legislative branch).

To understand the inefficiency associated with the fragmented nature of government, one can think of the manager of a public firm as responding to the pressure of different ministries or regulators (e.g., environmental and economic regulators). As in the common agency model of Section 4.1, the lack of coordination leads to excessive downward distortions of outputs because each regulator may have some veto rights on the firm's activities. Instead, in a private firm, shareholders act as intermediaries between the different regulators and the manager. Provided that contracting between the regulators and the shareholders takes place ex ante, i.e., before shareholders become informed, shareholders can be made residual claimant for the different sub-objectives of those regulators. This delegation can help shareholders to integrate and coordinate the conflicting demands of the regulators and reconstruct the incentive scheme of the manager as if the government were not fragmented.

Appraisal: That the control of a manager is more unified in the private than in the public sector is not necessarily a foregone conclusion. Indeed, the managers of private firms must also respond to several stakeholders from within (shareholders, debtholders, subsidiaries) but also outside the firm's boundaries (customers, input suppliers, regulators, labor market). It remains true, however, that the missions of the bureaucrats running public firms might include objectives other than profit maximization (e.g., redistributive ones) and that some of these dimensions of performance may be hard to measure. This could make explicit incentives harder to design in the public sphere. Also, the absence of an efficient labor market for managers in the public sector may reduce their reputational concerns and dampen their incentives.

\footnotetext{
${ }^{58}$ See Dewatripont, Jewitt and Tirole (1999).
} 


\section{Conclusion}

In this paper, I have presented a unified framework to discuss what Principal-Agent theory has to bring to the lively debate on privatization. This survey has been mostly methodological, focusing on simple models which can all fit into this unified framework. In doing so, I have deliberately omitted parts of the literature (the theory of ownership à la Grossman and Hart (1986) or the theory of transaction costs à la Williamson (1985) most noticeably) which are also relevant but would not be fit as well into the same framework. To maintain the paper's focus, I have also omitted specific topics such as the interaction between privatization and competition, the design of privatization procedures, or the empirical work on privatization.

The main message is that the Principal-Agent approach can be useful once it is amended to include enough frictions and incompleteness in contracting. Contrary to a common claim, the Principal-Agent approach can account for some incompletenesses and provide insights on the costs and benefits of privatization. Because it puts information asymmetries at the center of the analysis, this paradigm can account for the impact of the ownership structure on the distribution of information and thus on the level of constrained efficiency that various ownership arrangements achieve. Various contractual incompleteness (lack of commitment, limited State control, political economy considerations) affect the distribution of information between the public and the private sectors and therefore have a non-trivial impact on interim efficiency leading to either form of ownership to dominate.

All the models presented above seem to capture a relevant aspect of the privatization debate. However, all rely on incompleteness assumptions that affect both public and private ownership but to different degrees. This suggests that one should remain cautious in defending these assumptions. Theorizing on privatization remains a difficult and subtle exercise. 


\section{References}

Abreu, D. (1988), "Towards a Theory of Discounted Repeated Games", Econometrica, 56: 383-396.

Aghion, P. and J. Tirole (1997), "Formal and Real Authority in Organizations", Journal of Political Economy, 105: 1-29.

Armstrong, M. and D. Sappington (2003), "Recent Developments in the Theory of Regulation", mimeo UCL.

Arrow, K. (1975), "Vertical Integration and Communication", Bell Journal of Economics, 6: 173-183.

Auriol, E. and P. Picard (2004), "Privatizations in Developing Countries and the Government's Budget Constraint", mimeo IDEI.

Baron, D. (1989), "Design of Regulatory Mechanisms and Institutions", in R. Schmalensee, and R. Willig, eds., Handbook of Industrial Organization: Vol.2, North Holland.

Bennedsen, M. (2000), "Political Ownership", Journal of Public Economics, 76: $559-581$.

Besanko, D. and D. Spulber (1992), "Sequential Equilibrium Investment by Regulated Firms", Rand Journal of Economics, 23: 153-170.

Biais, B. and E. Perotti (2002), "Machiavellian Privatization", American Economic Review, 92: 240-258.

Bortolotti, B. and D. Siniscalco (2003), "The Challenges of Privatization: An international Analysis", Oxford University Press.

Che, J. and Y. Qian (1998), "Insecure Property Rights and Government Ownership of Firms", Quarterly Journal of Economics, 113: 467-496.

Demski, D. and D. Sappington (1991), "Resolving Double Moral Hazard Problems with Buyout Agreements", Rand Journal Economics, 22: 232-240.

Dewatripont, M. and E. Maskin (1995), "Credit and Efficiency in Centralized and Decentralized Economics", Review of Economic Studies, 62: 541-556.

Dewatripont, M., I. Jewitt and J. Tirole (1999), "The Economics of Career Concerns 2: Applications to Mission in Organizations", Review of Economic Studies, 66: 199-217.

Dixit, A. (1996), The Making of Economic Policy, MIT Press.

Faure-Grimaud, A. (2002), "Using Stock Price Information to Regulate Firms", Review of Economic Studies, 69: 169-190. 
Faure-Grimaud, A. and D. Martimort (2001), "The Agency Cost of Intermediated Contracting", Economics Letters, 71: 75-82.

Faure-Grimaud, A. and D. Martimort (2003), "Regulatory Inertia", Rand Journal of Economics, 34: 414-442.

Gilbert, R. and D. Newbery (1994), "The Dynamic Efficiency of Regulatory Institutions", Rand Journal of Economics, 25: 538-554.

Grossman, S. and O. Hart (1986), "The Costs and Benefits of Ownership: A Theory of Vertical and Lateral Integration", Journal of Political Economy, 94: 691-719.

Greenwald, B. (1984), "Rate Base Selection and the Structure of Regulation", Rand Journal of Economics, 15: 85-95.

Hart, O., A. Shleifer and R. Vishny (1997), "The Proper Scope of Government: Theory and an Application to Prisons", Quarterly Journal of Economics, 112: $1127-1161$.

Holmstrom, B. and P. Milgrom (1991), "Multi-Task Principal-Agent Analysis: Incentive Contracts, Assets Ownership and Job Design", Journal of Law, Economics and Organization, 7: 24-52.

Holmstrom, B. and R. Myerson (1983), "Efficient and Durable Decision Rules with Incomplete Information", Econometrica, 51: 1799-1819.

Kornai, J. (1986), "The Soft Budget Constraint", Kyklos, 39: 3-30.

Kornai, J., E. Maskin and G. Roland, (2003), "Understanding The Soft Budget Constraint", Journal of Economic Literature, 59: 1095-1136.

Laffont, J.J. (1996), "Industrial Policy and Politics", International Journal of Industrial Organization, 14: 1-27.

Laffont, J.J. (2005), Regulation and Development, Oxford University Press.

Laffont, J.J. and D. Martimort (2002), The Theory of Incentives: The PrincipalAgent Model, Princeton University Press.

Laffont, J.J. and D. Martimort (1999), "Separation of Regulators against Collusive Behavior", Rand Journal of Economics, 30: 232-262.

Laffont, J.J. and J. Tirole (1993), A Theory of Incentives in Procurement and Regulation, MIT Press.

Leland, H. and D. Pyle (1977), "Informational Asymmetries, Financial Structure and Financial Intermediation", The Journal of Finance, 32: 371-387.

Lewis, T. and D. Sappington (1995), "Optimal Capital Structure in Agency Relationship", Rand Journal of Economics, 26: 343-361. 
Lopez-de-Silanes, F., A. Shleifer and R. Vishny (1997), "Privatization in the United States", Rand Journal of Economcis, 28: 447-471.

Martimort, D. (1996), "The Multiprincipal Nature of the Government", European Economic Review, 40, 673-685.

Martimort, D. (1999), "Renegotiation with Multiple Regulators", Journal of Economic Theory, 88: 269-294.

Martimort, D. and W. Sand-Zantman (2004), "Signalling and the Design of Delegated Management for Public Utilities", mimeo IDEI.

Maskin, E. (1999), "Recent Theoretical Work on the Soft Budget Constgraint", American Economic Review, 89: 421-425.

Megginson, W., R. Nash and M. van Randenborgh (1994), "The Financial and Operating Performances of Newly Privatized Firms: An International Empirical Analysis", Journal of Finance, 49: 403-452.

Megginson, W. and J. Nettert (2001), "From State to Market: A Survey of Empirical Studies of Privatization", Journal of Economic Literature, 39: 321-389.

Perotti, E. (1995), "Credible Privatization", American Economic Review, 85: 847-859.

Riordan, M. (1990), "What is Vertical Integration", in M. Aoki, B. Gustaffson and O. Williamson, eds., The Firm as a Nexus of Treaties, Sage Publications.

Sappington, D. (1983), "Limited Liability Contracts between Principal and Agent", Journal of Economic Theory, 29: 1-21.

Sappington, D. and J. Stiglitz (1987), "Privatization, Information and Incentives", Journal of Policy Analysis and Management, 6: 567-582.

Savas, E. (1987), Privatization: The Keys to Better Government, Chatam House Publishers.

Schmidt, K. (1996), "The Costs and Benefits of Privatization: An Incomplete Contract Approach", Journal of Law, Economics and Organization, 12: $1-24$.

Segal, I. (1998), "Monopoly and Soft Budget Constraint", Rand Journal of Economics, 29: 596-609.

Shapiro, C. and R. Willig (1990), "Economic Rationales for the Scope of Privatization", J.M. Ohlin Program for the Study of Economic Organization and Public Policy: 41. 
Sheshinski, E. and L. Lopez-Calva (1999), "Privatization and its Benefits: Theory and Evidence", HIID Discussion Paper 698.

Shirley, M. and P. Walsh (2000), "Public vs. Private Ownership: The Current State of the Debate", mimeo, World Bank.

Shleifer, A., (1998), "State versus Private Ownership", Journal of Economic Perspectives, 12: 133-150.

Shleifer, A. and R. Vishny, (1994), "Politicians and Firms", Quarterly Journal of Economics, 109: 599-617.

Spiller, P. (1993), "Institutions and Regulatory Commitment in Utilities' Privatization", Industrial Corporate Change, 2: 317-380.

Williamson, O. (1985), The Economic Institutions of Capitalism, Free Press.

Wilson, J. (1989), What Bureaucracy Do and Why they Do it, Basic Books.

World Bank (1993), Subsidies and Directed Credits to Enterprises in Russia: A Strategy for Reform, Report $\mathrm{n}^{0}$ 11782-RU.

Yarrow, G., (1991), "Privatization in Theory and Practice", Economic Policy, 2: 324-364.

\section{Appendices}

Repeated Relationships to Alleviate Hold-Up Problems: Consider the following trigger strategies:

- If the regulator deviates from offering a transfer $t$ at any date, then the firm will neither produce nor invest at any future date.

- If the firm deviates from offering the quantity $q$ and investing $k$ at any date, then the regulator will not pay $t$ at any future date.

To sustain a subgame-perfect equilibrium where a triplet $(q, t, k)$ is implemented, two incentive constraints must be satisfied. For the State, following the equilibrium strategy yields the left-hand side below whereas the best deviation consists in not paying the transfer $t$, enjoying the surplus $S(q)$ in the current period and being punished forever from the next date on. This gives:

$S(q)-(1+\lambda) t+t-q(\theta-c(k))-r k+\sum_{i=1}^{\infty} \delta^{i}(S(q)-(1+\lambda) t+t-q(\theta-c(k))-r k) \geq S(q)$. 
For the firm, the corresponding incentive constraint is:

$$
t-q(\theta-c(k))-r k+\sum_{i=1}^{\infty} \delta^{i}(t-q(\theta-c(k))-r k) \geq 0 .
$$

The left-hand side is the discounted benefit from following the equilibrium strategy. If it deviates at a given date, the firm chooses not produce and, within that same date, the State starts the punishment strategy by not rewarding the firm.

These constraints can be rewritten respectively as (14) and (15) which together with the standard participation constraints define the set of incentive feasible contracts. ${ }^{59}$ Let us focus on the most favorable outcome from the State's point of view. It solves:

$$
\begin{gathered}
\max _{\{q, k, t\}} S(q)-(1+\lambda) t+t-q(\theta-c(k))-r k \\
\text { subject to (14) and (15). }
\end{gathered}
$$

When $\delta$ is close to one, the firm's incentive constraint alone is binding and the first-best efficient policy $\left\{q^{*}(\theta), k^{*}(\theta), t^{*}(\theta)\right\}$ defined as follows can be implemented

$$
\begin{aligned}
\frac{1}{1+\lambda} S^{\prime}\left(q^{*}(\theta)\right) & =\theta-c\left(k^{*}(\theta)\right), \\
q^{*}(\theta) c^{\prime}\left(k^{*}(\theta)\right) & =r \\
t^{*}(\theta) & =q^{*}(\theta)\left(\theta-c\left(k^{*}(\theta)\right)\right)+r k^{*}(\theta) .
\end{aligned}
$$

For such values of the discount factor, the State's incentive constraint is slack since the expected social welfare is strictly positive at the first-best, the regulator appropriates this whole value.

When $\delta$ is not as large, (14) and (15) are both binding and the second-best policy given by (16) and (17) is obtained.

Ex Post Bargaining between the Regulator and the Firm under Asymmetric Information: Assume that the manager privately knows $\theta$. To be consistent with the previous models, this assumption may be justified by the firm being private.

Contrary to Section 3.1, the price of the good is not set in the contract. Instead, it results of some ex post bargaining, taking place after the manager learns $\theta$ and chooses both $q$ and $k$. Hence, this is a setting with no commitment by the State.

To model bargaining, I use the Nash bargaining solution assuming equal bargaining weights for the regulator and the manager.

\footnotetext{
${ }^{59}$ Note that (15) is also the firm's participation constraint.
} 
As a benchmark, consider the case where $\theta$ is common knowledge. The transfer $t$ is set so that

$$
\max _{q}(S(q)-(1+\lambda) t)(t-q(\theta-c(k)))
$$

i.e.,

$$
t=\frac{1}{2}\left(\frac{S(q)}{1+\lambda}+q(\theta-c(k))\right)
$$

This transfer increases as the firm becomes less efficient. Anticipating this transfer, the firm's progam is:

$$
\max _{\{q, k\}} \frac{1}{2}\left(\frac{S(q)}{1+\lambda}-q(\theta-c(k))\right)-r k .
$$

Therefore, the second-best output is:

$$
\frac{S^{\prime}\left(q^{S B}(\theta)\right)}{1+\lambda}=\theta-c\left(k^{S B}(\theta)\right)
$$

whereas the second-best investment is distorted downwards and equal to

$$
\frac{1}{2} q^{S B}(\theta) c^{\prime}\left(k^{S B}(\theta)\right)=r
$$

and the corresponding transfer is:

$$
t^{S B}(\theta)=\frac{1}{2}\left(\frac{S\left(q^{S B}(\theta)\right)}{1+\lambda}+q^{S B}(\theta)\left(\theta-c\left(k^{S B}(\theta)\right)\right)\right) .
$$

Indeed, since the ex post gains from trade are shared equally between the State and the firm, the manager sets production at an efficient level for a given level of investment. However, since the manager incurs the cost of investment before bargaining, he only receives half of the benefits and underinvestment follows. The hold-up problem arises again.

Let us show how asymmetric information on $\theta$ can, at least partially, alleviate this holdup problem. Consider the sequential moves game where the privately informed manager moves first and chooses output and investment before bargaining. That first stage of the game certainly conveys information to the State about $\theta$.

I will focus on separating equilibria. Those perfect Bayesian equilibria are sustained with optimistic beliefs such that any out-of-equilibrium output-investment pair is interpreted as coming from an efficient firm. In these equilibria, the difficulty stems from the efficient manager's temptation to mimic an inefficient one to receive the large regulatory transfer defined in (32).

Denote $(\underline{t}, \underline{q}, \underline{k})$ and $(\bar{t}, \bar{q}, \bar{k})$ the equilibrium allocation of both types of firm. From the specification of the out-of-equilibrium beliefs made above, it must be that $(\underline{t}, \underline{q}, \underline{k})=$ $\left(t^{S B}(\underline{\theta}), q^{S B}(\underline{\theta}), k^{S B}(\underline{\theta})\right)$. 
In a separating equilibrium, the following incentive constraint must also hold

$$
\underline{t}-\underline{q}(\underline{\theta}-c(\underline{k}))-r \underline{k} \geq \bar{t}-\bar{q}(\underline{\theta}-c(\bar{k}))-r \bar{k},
$$

or using the expressions of transfers given in (32)

$\frac{1}{2}\left(\frac{S\left(q^{S B}(\underline{\theta})\right)}{1+\lambda}-q^{S B}(\underline{\theta})\left(\underline{\theta}-c\left(k^{S B}(\underline{\theta})\right)\right)\right)-r k^{S B}(\underline{\theta}) \geq \Delta \theta \bar{q}+\frac{1}{2}\left(\frac{S(\bar{q})}{1+\lambda}-\bar{q}(\bar{\theta}-c(\bar{k}))\right)-r \bar{k}$.

This constraint is relaxed when $\bar{q}$ is reduced and $\bar{k}$ is increased. Therefore, the best separating equilibrium from the point of view of an inefficient manager must satisfy: ${ }^{60}$

$$
\begin{aligned}
\max _{\{\bar{q}, \bar{k}\}} \bar{t}-r \bar{k} \equiv & \frac{1}{2}\left(\frac{S(\bar{q})}{1+\lambda}+q(\bar{\theta}-c(\bar{k}))\right)-r \bar{k} \\
& \text { subject to }(37) .
\end{aligned}
$$

Some distortions arise for signalling reasons. Denoting by $\mu$ the multiplier of the incentive constraint (37), ${ }^{61}$ I find:

$$
\frac{S^{\prime}\left(q^{A I}(\bar{\theta})\right)}{1+\lambda}-\bar{\theta}+c\left(k^{A I}(\bar{\theta})\right)=\frac{\mu}{1-\mu} \Delta \theta
$$

and

$$
\frac{1}{2} q^{A I}(\bar{\theta}) c^{\prime}\left(k^{A I}(\bar{\theta})\right)=r
$$

Note that $q^{A I}(\bar{\theta})$ (resp. $k^{A I}(\bar{\theta})$ ) is distorted downwards (resp. upwards) to relax the signalling's incentive constraint.

Hard Budget Constraint without Monetary Transfers: First, consider the case of a public firm receiving monetary transfers from the State: the relevant incentive and participation constraints under asymmetric information on $\theta$ are written as:

$$
\begin{aligned}
\underline{U} & =\underline{t}+(P(\underline{q})-\underline{\theta}) \underline{q}-K_{0}+d(I) \geq \bar{U}+\Delta \theta \bar{q}, \\
\bar{U} & =\bar{t}+(P(\bar{q})-\bar{\theta})-K_{0}+d(I) \geq 0 .
\end{aligned}
$$

The government's problem can therefore be written as:

$$
\max _{\{(\underline{t}, \underline{q}, \underline{U}) ;(\bar{t}, \bar{q}, \bar{U})\}} \nu(S(\underline{q})-P(\underline{q}) \underline{q}-(1+\lambda) \underline{t}+\underline{U})+(1-\nu)(S(\bar{q})-P(\bar{q}) \bar{q}-(1+\lambda) \bar{t}+\bar{U})
$$

$$
\text { subject to (38) and (39). }
$$

\footnotetext{
${ }^{60}$ The firm's participation constraint can be omitted (at least when $\Delta \theta$ is small enough) since the firm gets half of (almost) the first-best surplus which is supposed to be positive with both types.

${ }^{61}$ This multiplier is necessarily less than 1 when $\Delta \theta$ is small enough.
} 
Maximizing this expression gives the following formulae for Ramsey pricing:

$$
P\left(q^{P u}(\underline{\theta})\right)-\underline{\theta}=-\frac{\lambda}{1+\lambda} P^{\prime}\left(q^{P u}(\underline{\theta})\right) q^{P u}(\underline{\theta}),
$$

and

$$
P\left(q^{P u}(\underline{\theta})\right)-\left(\underline{\theta}+\frac{\nu}{1-\nu} \frac{\lambda}{1+\lambda} \Delta \theta\right)=-\frac{\lambda}{1+\lambda} P^{\prime}\left(q^{P u}(\bar{\theta})\right) q^{P u}(\bar{\theta}) .
$$

Constraints (38) and (39) are binding, and the information rents of both types are

$$
U^{P u}(\underline{\theta})=\Delta \theta q^{P u}(\bar{\theta}) \quad \text { and } \quad U^{P u}(\bar{\theta})=0 .
$$

If the firm is private $(\underline{t}=0 ; \bar{t}=0)$ and $K_{0}$ is large enough so that (38) and (39) are both binding we get:

$$
\begin{aligned}
\underline{U} & =(P(\underline{q})-\underline{\theta}) \underline{q}-K_{0}+d(I)=\Delta \theta \bar{q} \\
\bar{U} & =(P(\bar{q})-\bar{\theta}) \bar{q}-K_{0}+d(I)=0 .
\end{aligned}
$$

From which we get $\underline{q}=\bar{q}=q^{P r}(I)$ defined by (22).

The private firm maximizes $\nu \Delta \theta q^{P r}(I)-I$ and one finds (23).

Nash-Equilibria with Multiprincipals: Denote by $\{(\bar{q}, \bar{t}, \bar{z}) ;(\underline{q}, \underline{t}, \underline{z})\}$ any such equilibrium allocation. A number of necessary conditions can be derived to characterize these allocations. ${ }^{62}$

First, the regulator's best-response to the dividend scheme offered by shareholders is obtained as a solution to the following problem:

$$
\begin{gathered}
\max _{\{\underline{q}, \underline{U}) ;(\bar{q}, \bar{U})\}}(1+\lambda) \Delta+\nu(S(\underline{q})-\lambda z(\underline{q})-(1+\lambda) \underline{\theta} \underline{q})+(1-\nu)(S(\bar{q})-\lambda z(\bar{q})-(1+\lambda) \bar{\theta} \bar{q}) \\
-\lambda(\nu \underline{U}+(1-\nu) \bar{U})
\end{gathered}
$$

subject to (1), (2), (7) and (8).

Similarly, the shareholders' best-response to the regulatory scheme solves

$$
\begin{gathered}
\max _{\{(\underline{q}, \underline{U}) ;(\bar{q}, \bar{U})\}} \nu(\Delta+t(\underline{q})-\underline{\theta} \underline{q})+(1-\nu)(\Delta+t(\bar{q})-\bar{\theta} \bar{q})-(\nu \underline{U}+(1-\nu) \bar{U}) \\
\text { subject to }(1),(2),(7) \text { and }(8) .
\end{gathered}
$$

Given two nonlinear schemes $z(q)$ and $t(q)$, the agent must also make the equilibrium choices of output, meaning that

$$
\underline{q} \in \arg \max _{q} t(q)-z(q)-\underline{\theta} q+\Delta,
$$

\footnotetext{
${ }^{62}$ It is easy to check that those conditions are also sufficient and that simple forcing contracts enforce those allocations at equilibrium.
} 
and

$$
\bar{q} \in \arg \max _{q} t(q)-z(q)-\bar{\theta} q+\Delta .
$$

By maximization of the regulator's objective, it must be that ${ }^{63}$

$$
S(\underline{q})-(1+\lambda) \underline{\theta} \underline{q}-\lambda \underline{z} \geq S(\bar{q})-(1+\lambda) \underline{\theta} \bar{q}-\lambda \bar{z},
$$

so that the regulator induces the right equilibrium output choice $\underline{q}$ by the efficient firm.

Similarly, it must be that the regulator does not want to "shut-down" the inefficient firm, meaning that the realized social surplus with that type is non-negative

$$
S(\bar{q})-(1+\lambda) \bar{\theta} \bar{q}-\lambda \bar{z}+(1+\lambda) \Delta-\frac{\nu}{1-\nu} \lambda \Delta \bar{q} \geq 0 .
$$

That condition captures also the fact that the regulator may find optimal to veto the production by the inefficient firm if the dividends taken by shareholders are too high.

One could also derive similar inequalities to characterize the shareholders' best-response to the regulatory contract. These inequalities are respectively given by

$$
\underline{t}-\underline{\theta} \underline{q} \geq \bar{t}-\underline{\theta} \bar{q}
$$

and

$$
\bar{t}-\bar{\theta} \bar{q}-\frac{\nu}{1-\nu} \Delta \theta \bar{q}+\Delta \geq 0
$$

That latter condition means that shareholders do not veto production by the inefficient firm if the regulatory subsidy is large enough.

Constraints (42) to (45) plus the binding incentive and participation constraints of the firm, namely

$$
\begin{aligned}
\underline{U} & =\underline{t}-\underline{z}-\underline{\theta} \underline{q}=\bar{t}-\bar{z}-\underline{\theta} \bar{q}=\bar{U}+\Delta \theta \bar{q}, \\
\bar{U} & =\bar{t}-\bar{z}-\bar{\theta}=q \geq 0,
\end{aligned}
$$

define the possible equilibrium values of the transfers and outputs.

Using (42), (44) and (46), we see that an output pair $(\underline{q}, \bar{q})$ is implementable in a Nash equilibrium of the common agency game when (24) holds. Similarly, using (43), (45) and (47), we get the "aggregate veto" constraint (25) characterizing the outputs that can be produced by the inefficient firm.

The planner must solve:

$$
\max _{\{\underline{q}, \bar{q}\}} \nu(S(\underline{q})-(1+\lambda) \underline{\theta} \underline{q}-\lambda \Delta \theta \bar{q})+(1-\nu)(S(\bar{q})-(1+\lambda) \bar{\theta} \bar{q}),
$$

\footnotetext{
${ }^{63}$ We focus here on upward incentive compatible constraints which are the only relevant ones.
} 
subject to (24) and (25),

and we get condition (26).

Endogenous Governance: Under public ownership, the risk-averse State having a Bernoulli utility function $v(\cdot)\left(v^{\prime}>0, v^{\prime \prime}<0\right)$ must now solve:

$$
\max _{\{(\underline{q}, \underline{U}) ;(\bar{q}, \bar{U})\}} \nu v(S(\underline{q})-(1+\lambda) \underline{t}+\underline{U})+(1-\nu) v(S(\bar{q})-(1+\lambda) \bar{t}+\bar{U})
$$

subject to (1), (2), (7) and (8).

Clearly, only (1) and (8) are binding at the optimum of this problem. Only the efficient firm gets a positive rent $U^{P u}(\underline{\theta})=\Delta \theta q^{P u}(\bar{\theta})$ where the inefficient firm's output is now given by

$$
\frac{1}{1+\lambda} S^{\prime}\left(q^{P u}(\bar{\theta})\right)=\bar{\theta}+\frac{\lambda}{1+\lambda} \frac{\nu}{1-\nu} \frac{v^{\prime}\left(V^{P u}(\underline{\theta})\right)}{v^{\prime}\left(V^{P u}(\bar{\theta})\right)} \Delta \theta
$$

with

$$
V^{P u}(\underline{\theta})=S\left(q^{*}(\underline{\theta})\right)-(1+\lambda) \underline{\theta} q^{*}(\underline{\theta})-\lambda \Delta \theta q^{P u}(\bar{\theta})
$$

and

$$
V^{P u}(\bar{\theta})=S\left(q^{P u}(\bar{\theta})\right)-(1+\lambda) \bar{\theta} q^{P u}(\bar{\theta}) .
$$

The State's payoff is higher when the firm is efficient $\left(V^{P u}(\underline{\theta})>V^{P u}(\bar{\theta})\right)$ and the distortion $q^{P u}(\bar{\theta})$ is thus lower than $q^{S B}(\bar{\theta})$, the corresponding distortion in the case of a risk-neutral State.

Under private ownership, the State's problem is now

$$
\max _{\{(\underline{q}, \underline{U}, \underline{z}) ;(\bar{q}, \bar{U}, \bar{z})\}} \nu v(S(\underline{q})-(1+\lambda) \underline{t}+\underline{U}+\underline{z})+(1-\nu) v(S(\bar{q})-(1+\lambda) \bar{t}+\bar{U}+\bar{z})
$$

subject to (1), (2), (7), (8) and (27).

There exists a unique pair $\left(\underline{z}^{P r}, \bar{z}^{P r}\right)$ so that the State gets full insurance and the investors break-even:

$$
\underline{z}^{P r}=\frac{(1-\nu)}{\lambda}\left\{\left(S\left(q^{*}(\underline{\theta})\right)-(1+\lambda) \underline{\theta} q^{*}(\underline{\theta})\right)-\Delta \theta q^{S B}(\bar{\theta})-\left(S\left(q^{S B}(\bar{\theta})\right)-(1+\lambda) \bar{\theta} q^{S B}(\bar{\theta})\right)\right\}
$$

and

$$
\bar{z}^{P r}=-\frac{\nu}{1-\nu} \underline{z}^{P r}
$$

Privatization to Reduce the Discretion of Biased Principals: Under public ownership, the optimal contract with ex post contracting is solution to:

$$
\max _{\{(\underline{q}, \underline{U}) ;(\bar{q}, \bar{U})\}} \nu\left(\frac{1}{1+\lambda} S(\underline{q})-\underline{\theta} \underline{q}\right)+(1-\nu)\left(\frac{1}{1+\lambda} S(\bar{q})-\bar{\theta} \bar{q}\right)-\left(1-\frac{\beta}{1+\lambda}\right)(\nu \underline{U}+(1-\nu) \bar{U})
$$


subject to (1), (2), (7) and (8).

The optimal output for an inefficient firm is then given by (28).

Consider now the case of private ownership. Given a regulatory contract $\{t(\hat{\phi}), q(\hat{\phi})\}$ stipulating transfer and output as a function of the report $\hat{\phi}$ made by shareholders on the efficiency parameter, the shareholders' problem is to optimize reports $\underline{\phi}$ and $\bar{\phi} \cdot{ }^{64}$ Given that asymmetric information affects the relationship of the shareholders with the firm's manager, those manipulations are unlikely to be ex post efficient.

Typically, the shareholders' problem can be written as:

$$
\max _{\{(\underline{\phi}, \underline{U}) ;(\bar{\phi}, \bar{U})\}} \nu(t(\underline{\phi})-\underline{\theta} q(\underline{\phi}))+(1-\nu)(t(\bar{\phi})-\bar{\theta} q(\bar{\phi}))-(\nu \underline{U}+(1-\nu) \bar{U})
$$

subject to (1), (2), (7) and (8).

Writing down the truth-telling conditions (i.e., $\underline{\phi}^{*}=\underline{\theta}$ and $\bar{\phi}^{*}=\bar{\theta}$ ) yields the coalition incentive constraints:

$$
\begin{aligned}
\underline{t}-\underline{\theta} \underline{q} & \geq \bar{t}-\underline{\theta} \bar{q} \\
\bar{t}-\left(\bar{\theta}+\frac{\nu}{1-\nu} \Delta \theta\right) \bar{q} & \geq \underline{t}-\left(\bar{\theta}+\frac{\nu}{1-\nu} \Delta \theta\right) \underline{q} .
\end{aligned}
$$

Because shareholders may decide to shut-down the inefficient firm, one must also have:

$$
\bar{t}-\left(\bar{\theta}+\frac{\nu}{1-\nu} \Delta \theta\right) \bar{q} \geq 0
$$

Since the political principal is a Stackelberg leader who anticipates the private contract between shareholders and the manager, his problem can be written as:

$$
\begin{gathered}
\max _{\{(\underline{t}, \underline{q}) ;(\bar{t}, \bar{q})\}} \nu(S(\underline{q})-(1+\lambda) \underline{t}+\beta \Delta \theta \bar{q})+(1-\nu)(S(\bar{q})-(1+\lambda) \bar{t}) \\
\text { subject to }(49) \text { to }(51) .
\end{gathered}
$$

The solution to this problem is such that

- There is no distortion for the efficient firm: it produces the first-best quantity $q^{*}(\underline{\theta})$.

- There is a stronger distortion than under public ownership for the inefficient firm, i.e., $q^{P r}(\bar{\theta})<q^{P u}(\bar{\theta})$ where $q^{P u}(\bar{\theta})$ solves $(29)$.

\footnotetext{
${ }^{64}$ This is the "direct revelation mechanism" version of the regulatory game. In practice the regulatory contract is a nonlinear scheme $t(q)$. What the shareholders want to do then is to design an incentive mechanism with the firm's manager to choose the outputs $\underline{q}$ and $\bar{q}$.
} 
Partisan Politics: When $P_{1}$ holds office, the optimal contract solves now

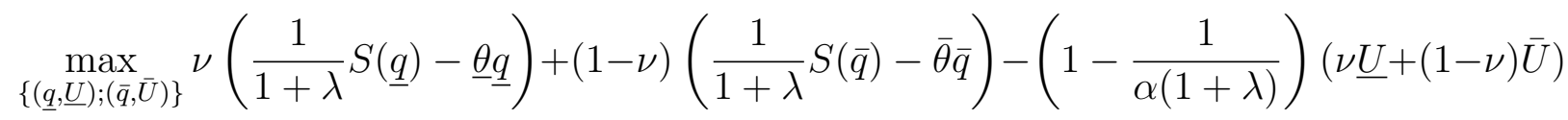

subject to (1), (2), (7) and (8)

which yields (30). 